Document downloaded from:

http://hdl.handle.net/10251/165301

This paper must be cited as:

Butts, IAE.; Hilmarsdóttir, GS.; Zadmajid, V.; Gallego Albiach, V.; Stottrup, JG.; Jacobsen, C.; Krüger-Johnsen, M.... (2020). Dietary amino acids impact sperm performance traits for a catadromous fish, Anguilla anguilla reared in captivity. Aquaculture. 518:1-12.

https://doi.org/10.1016/j.aquaculture.2019.734602

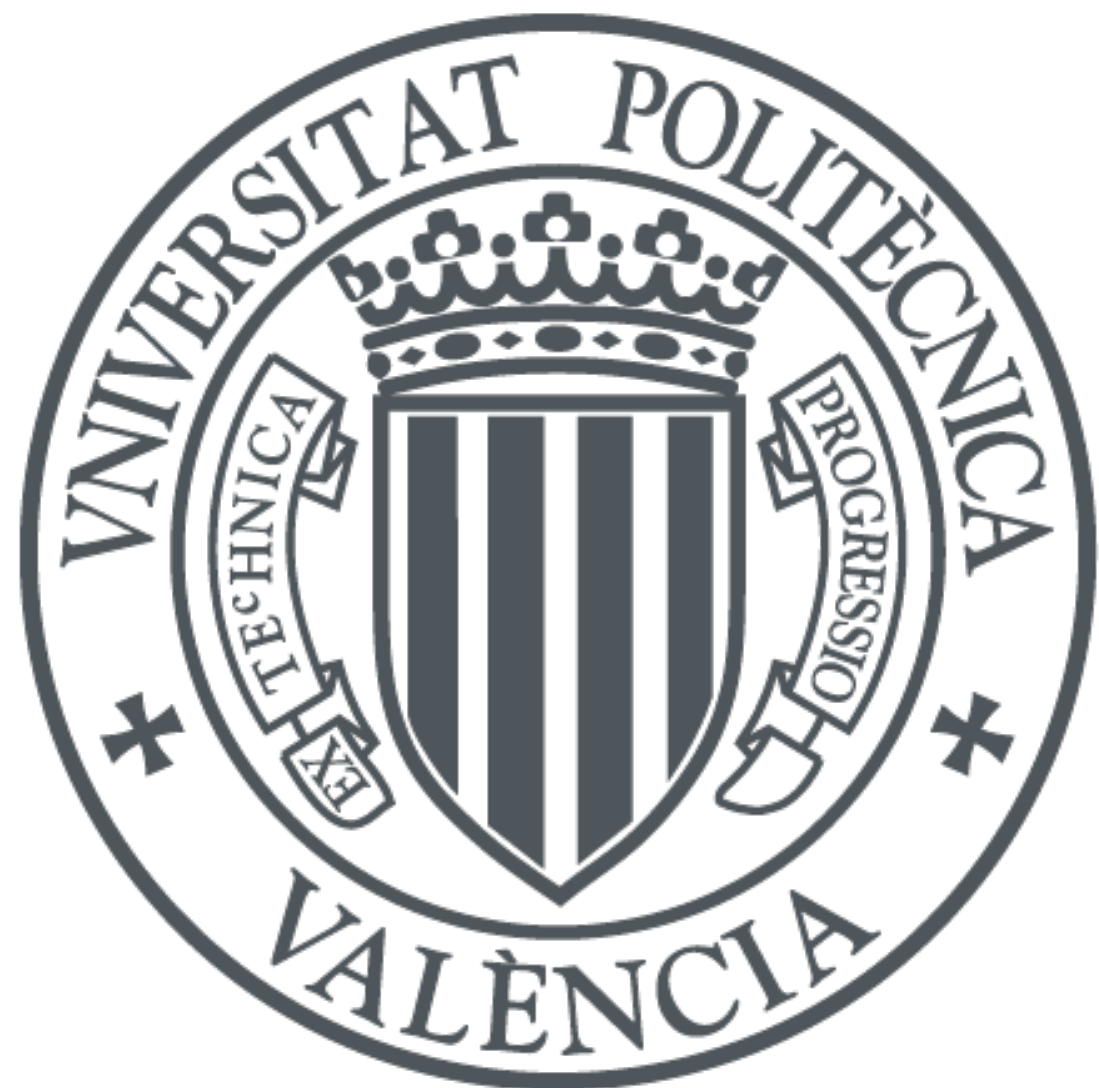

The final publication is available at

https://doi.org/10.1016/j.aquaculture.2019.734602

\title{
Copyright Elsevier
}

Additional Information

Systematic reproduction and distribution, duplication of any material in this paper for a fee or for commercial purposes, or modifications of the content of this paper are prohibited. 
2 Dietary amino acids impact sperm performance traits for a catadromous fish, Anguilla

3 anguilla reared in captivity

4

5 Ian Anthony Ernest Butts ${ }^{1,2^{*}}$, Guðrún Svana Hilmarsdóttir ${ }^{2,3}$, Vahid Zadmajid ${ }^{4}$, Victor Gallego ${ }^{5}$,

6 Josianne G. Støttrup ${ }^{2}$, Charlotte Jacobsen ${ }^{3}$, Maria Krüger-Johnsen², Sebastian N. Politis ${ }^{2}$, Juan F.

$7 \quad$ Asturiano $^{5}$, Jonna Tomkiewicz ${ }^{2}$

8

$9{ }^{1}$ School of Fisheries, Aquaculture, and Aquatic Sciences, Auburn University, Auburn, Alabama,

10 USA

$11{ }^{2}$ National Institute of Aquatic Resources, Technical University of Denmark, Kgs. Lyngby,

12 Denmark

$13{ }^{3}$ National Food Institute, Technical University of Denmark, Kgs. Lyngby, Denmark

$14{ }^{4}$ Department of Fisheries Science, Faculty of Natural Resources, University of Kurdistan,

15 Sanandaj, Iran

$16{ }^{5}$ Grupo de Acuicultura y Biodiversidad. Instituto de Ciencia y Tecnología Animal. Universitat

17 Politècnica de València, Valencia, Spain

18

$19 *$ Corresponding author

20 Ian Anthony Ernest Butts

21 E-mail: iab0007@auburn.edu

22

23 


\section{Abstract}

26 Little is known about the role of dietary amino acids on male reproductive performance and gamete

27 quality in fishes. Thus, the objective of this study was to investigate how "enhanced" feeds (EH-

28 4, EH-5, EH-6), with modified amino acid composition, and the standard on-growing diet (DAN-

29 EX) impact body composition, milt biochemistry, and sperm performance in male European eel,

30 Anguilla anguilla. The fatty acid composition of EH-4, EH-5, and EH-6 was similar but differed

31 to that in DAN-EX, while amino acid composition varied between all four diets. Diet did not

32 influence organ-somatic indices (e.g. HSI, GSI), while males fed EH-4 were heavier than other

33 groups. Arginine, alanine, and lysine were the most abundant amino acids in milt (>11\%), followed

34 by glycine, aspartic acid, valine, glutamic acid, and leucine ( $>5.66 \%)$. Diet impacted milt arginine,

35 serine, proline, methionine, and histidine levels. Specifically, males fed DAN-EX, EH-4, and EH-5

36 had the highest percentages of arginine, while males fed EH-4 to EH-6 had higher percentages of

37 serine. Proline was most abundant in males fed DAN-EX, EH-5, and EH-6. Both methionine and

38 histidine were detected at low percentages $(<2 \%)$, and were impacted by diet, where males fed

39 EH-4 and EH-5 had higher percentages of methionine, and males fed DAN-EX, EH-4, and EH-6

40 had the highest percentage of histidine. Milt production increased over time, where eels fed EH-4

41 and EH-6 showed the highest probability of producing suited milt volumes $(>0.5 \mathrm{~mL})$ for

42 fertilization procedures. Spermatocrit $(43.1 \pm 1.80 \%)$ did not differ between the diets (ranged from

$43 \quad 37.57$ to $47.21 \%$ ). Dietary regime had an impact on sperm motility, such that eels fed EH-5 and

44 EH-6 had the greatest percentage of motile cells. In addition, fish fed EH-5 and EH-6 (or DAN-

45 EX) had the fastest swimming sperm. Spermatogenic maturity index of hormonally treated eels

46 varied within groups but did not differ between dietary treatment groups after 9 weeks of injections 
47 (ranged from 0.54 to 0.80 ). The most interesting amino acids to scrutinize from PCA plots were

48 proline, histidine, and valine as well as lysine and arginine. Here, eels with highly motile sperm

49 had milt with high relative proportions of proline, histidine, and valine, but were particularly low

50 in lysine and arginine. Together, our findings add evidence that certain amino acids regulate milt

51 biochemistry, and that male ejaculate traits may be promoted by amino acid intake. Further studies

52 to evaluate effects of supplemented amino acid diets on fertilization ability and inter-linked early

53 developmental stages are required.

55 Keywords: Aquaculture; Broodstock diet; Assisted Reproduction; Gamete quality; European eel

\section{1. Introduction}

When reared in captivity, fishes may exhibit different degrees of reproductive dysfunction,

60 such as spermiation failure, spontaneous ovulation, or decreases in gamete quality (Mylonas et al.,

61 2017). Poor gamete quality may jeopardize the survival of offspring, especially during the

62 "critical" early life history stages, which can ultimately impact aquaculture production and limit

63 possibilities for selective breeding (Bromage et al., 1992; Kjørsvik et al., 2003). Therefore, a stable

64 supply of "high-quality" gametes is required for establishment of sustainable culture for any given

65 species. In this scenario, controlling sperm quality can be a major issue for the aquaculture

66 industry, since it is affected by a variety of factors including broodstock nutrition, epigenetics,

67 and/or sperm handling (Cabrita et al., 2014).

68 It is widely accepted that broodstock nutrition or enriched diets with certain compounds

69 greatly modulate sperm physiology and functionality (Labbé et al., 1995; Lahnsteiner et al., 2009; 
70 Beirão et al., 2015) as well as male reproductive success (Asturiano et al., 2001). In this regard,

71 most studies have supplemented diets with modified lipid and fatty acid profiles (Asturiano et al.,

72 2001; Vassallo-Agius et al., 2001; Nandi et al., 2007; Cabrita et al., 2014; Beirão et al., 2015).

73 While manipulation of lipids in broodstock diets offers excellent opportunities to improve gamete

74 quality, the protein and amino acids should similarly receive consideration. The biological

75 functionality of amino acids is diverse, as they are involved in feed intake, nutrient utilization, and

76 reproduction (Izquierdo et al., 2001; Li et al., 2009; Wu, 2009). Additionally, they are precursors

77 for a wide variety of macromolecules, such as nucleotides, lipids, glycogen, steroids (Finn and

78 Fyhn, 2010), and serve as oxidizable substrates for sperm (Mann and Lutwak-Mann, 1981).

Evidence has accumulated that amino acids are highly beneficial for improving reproduction

80 and directly affect fertilization success and the number of viable embryos (Amirkhanov, 1980;

81 Dabrowski et al., 1985; Kwasek et al., 2014a). For example, certain amino acids (e.g. arginine) are

82 abundant in physiological fluids (Wu et al., 2009) and play a crucial role in regulating reproductive

83 functions (Li et al., 2009), survival of juvenile fish (Buentello and Gatlin, 2001), as well as

84 neuronal development and neurotransmission (Jobgen et al., 2006; Yao et al., 2008). Additionally,

85 in fish, amino acid-rich proteins called protamines within sperm nuclei are involved in sperm cell

86 growth and differentiation (Martinage et al., 1985), thus underlining a critical role for amino acids

87 in spermatogenesis (Wu et al., 2009). Previous studies reported that taurine (derived from cysteine)

88 at levels of $10 \mathrm{~g} / \mathrm{kg}$ improved spawning in some marine fish species (Matsunari et al., 2006). In

89 Japanese eel, Higuchi et al. (2012) determined that taurine is essential for spermatogenesis,

90 although it can be synthetized from cysteine in the testis under the action of dihydroxyprogesterone

91 (DHP). The consequences of dietary supplementation of amino acids on male gamete quality and

92 performance are fascinating, due to the fact that amino acids are a key component of seminal 
93 plasma and sperm (Lahnsteiner 2009, 2010; Kwasek et al., 2014b), impacting sperm metabolism

94 and sperm motility and/or fertility (Patel et al., 1998; He and Woods, 2003). In addition, a complex

95 antioxidant defense system exists in milt (e.g. superoxide dismutase, catalase, and the glutathione

96 peroxidase-glutathione reductase system), which is highly influenced by nutrition (Mansour et al.,

97 2006). Thus, dietary supplementation of specific amino acids may provide a novel approach to

98 improve fertility in males.

99 Sperm performance and composition in vertebrates are clearly affected by dietary 100 supplementation of amino acids (Wu et al., 2009; Kwasek et al., 2014b; Pourkhazaei et al., 2017).

101 For example, in mammals, either supplementation of diets with amino acids or direct injection 102 improved sperm traits (e.g. motility, velocity, morphologically normal sperm, and acrosome 103 integrity) and subsequent fertilization success (Dong et al., 2016; Abd-Elrazek and Ahmed-Farid, 104 2018). In teleosts, only a few studies have investigated incorporation of dietary amino acids on 105 male gonadal development and gamete quality (Akiyama et al., 1996; Kwasek et al., 2014b; 106 Pourkhazaei et al., 2017), and without directly linking the diet to the kinetic characteristics of 107 sperm. As such, knowledge regarding the role of dietary amino acids on gamete quality and 108 reproductive performance of male fish remains incomplete.

109 Here, we use European eel, Anguilla anguilla as our model organism. Despite increasing 110 efforts (Asturiano et al., 2005; Gallego et al., 2012; Tomkiewicz, 2012; da Silva et al., 2018; Politis 111 et al., 2018a; Benini et al., 2018), variability in gamete quality is still an issue affecting larval 112 production for this species. During the last decade, different strategies have been employed to 113 improve European eel gamete quality, especially by conducting studies on reproductive 114 performance and broodstock diets at specific developmental windows (Støttrup et al., 2013; Baeza 115 et al., 2014, 2015a,b; Butts et al., 2015; da Silva et al., 2016). For example, supplementation of 
116 broodstock diets with lipids [mainly polyunsaturated fatty acid (PUFA)], improved spermiation

117 and milt quality in males (Butts et al., 2015), and oocyte growth and ovarian development in

118 females (Støttrup et al., 2016; da Silva et al., 2016). Therefore, further information on the effects

119 of broodstock diets on European eel gamete performance could enhance the process of 120 domestication for mass production of larvae. Nevertheless, the effect of supplementation of the

121 broodstock diet with amino acids on gamete quality has not yet been investigated for this species.

122 As such, we hypothesize that dietary supplementation of specific amino acids will be beneficial

123 for male gamete performance.

124 The objective of this study was to investigate how "enhanced" feeds (EH-4, EH-5, EH-6),

125 with modified amino acid composition, and the standard on-growing diet (DAN-EX) impact body

126 composition, milt biochemistry, and sperm performance in male European eel. Together, these 127 data may be used to improve broodstock diets for this catadromous fish and increase our 128 understanding on reproductive physiology in fishes.

\section{Materials and methods}

133 protection of experimental animals (Dir 86/609/EEC). Eel experimental protocols were approved 134 by the Animal Experiments Inspectorate (AEI), Danish Ministry of Food, Agriculture and 135 Fisheries (permit number: 2015-15-0201-00696). All efforts were made to minimize animal 136 handling and stress. 


\subsection{Eel broodstock husbandry}

Eels were raised from wild-caught glass eels in a commercial eel farm, Stensgården Eel Farm

$142 \mathrm{~A} / \mathrm{S}$ in Jutland, Denmark. Eels were grown on commercial feed (DAN-EX; BioMar A/S, Brande,

143 Denmark) in concrete tanks $\left(18-30 \mathrm{~m}^{3}\right)$ at stocking density of $\sim 50 \mathrm{~kg} / \mathrm{m}^{2}$. Rearing tanks were

144 equipped with recirculating aquaculture system (RAS) technology, which consisted of a rotating 145 drum filter, biofilter, trickle-filters, UV system, and oxygen cones. Water was salted to 1-2 PSU 146 and heated to $23 \pm 2{ }^{\circ} \mathrm{C}$. Upon start of experimental trials, the eels were sorted based on size and 147 then transferred to 4 fiberglass tanks $\left(2 \times 2 \mathrm{~m}\right.$, volume of $2.5 \mathrm{~m}^{3}$, flowrate 1.5 to $\left.2 \mathrm{~m}^{3} / \mathrm{h}\right)$ at an 148 initial stocking density of $50 \mathrm{~kg} / \mathrm{m}^{2}$. Males were fed with automatic feeders six times per day at 1490.5 to $0.8 \%$ body weight from 1 August 2015 to 2 February 2016 on three "enhanced" feeds (EH-4, 150 EH-5, EH-6; Table 1) and the standard on-growing diet (DAN-EX) varying in fatty acid (Table 2) 151 and amino acid composition (Table 3 ). Final stocking density was $\sim 80 \mathrm{~kg} / \mathrm{m}^{2}$.

153 randomly selected and transported to a Technical University of Denmark (DTU Aqua) research 154 facility in Hirtshals, Denmark $(57.585971 \mathrm{~N}, 9.985036 \mathrm{E})$. The eels were housed in $4 \times 500 \mathrm{~L}$ 155 tanks equipped with RAS technology at a flowrate of $600 \mathrm{~L} / \mathrm{h}$. The RAS system consisted of a 350 156 L gravel filter, $0.3 \mathrm{~m}^{3}$ trickle filter, and a $300 \mathrm{~L}$ temperature regulated sump. Temperature ranged 157 between $19-21^{\circ} \mathrm{C}$, salinity ranged from 36-37 PSU, and photoperiod was kept at $12 \mathrm{~h}$ light/12 h 158 dark at $\sim 20$ lux. Natural seawater salinity of $\sim 32.5$ PSU from the North Sea was adjusted using 159 Tropic Marin Sea Salt (Dr. Biener GmbH, Wartenberg, Germany) and verified using a 160 conductivity meter (WTW multi3410, Wissenschaftlich-Technische Werkstätten GmbH, 161 Weilheim, Germany). Acclimatization to sea water took place over one week before entering the 
162 facility. No feed was provided during experimentation as eels cease feeding during the silvering

163 process and are not anticipated to feed during spawning migration (Tesch, 2003).

164 After acclimatization, 32 randomly selected males ( 8 per diet, $>100 \mathrm{~g}$ ) were euthanized by

165 submergence in an aqueous solution of benzocaine and their body weight and length were recorded

166 to get an indication of their morphological status after receiving the experimental diets. These 32

167 eels were also dissected and liver weight was obtained. The remaining eels $(n=97)$ were

168 anaesthetized by short-term submergence in benzocaine and tagged with a passive integrated

169 transponder (PIT tag). The PIT tag was placed in the dorsal muscle. Male eels from each diet

170 (DAN-EX $=27, \mathrm{EH}-4=25, \mathrm{EH}-5=25, \mathrm{EH}-6=20)$ received weekly injections of human chorionic

171 gonadotropin (hCG, Sigma Aldrich Denmark A/S) at $1.5 \mathrm{IU} / \mathrm{g}$ fish in order to induce milt

172 production (Pérez et al., 2000). Body weight was recorded at the time of first injection and then at

173 injection Week 4, Week 7, and Week 9. In addition, $24 \mathrm{~h}$ after the Week 9 injection, 8-9 males

174 were randomly selected per diet. Among these, the spermiating males ranged between 94-126 $\mathrm{g}$.

175 Again, after eels were euthanized, body weight, testes weight, and liver weight were recorded.

176 Gonadosomatic index (GSI; $100 \times$ testes weight/body weight) and hepatosomatic index (HSI; 100

$177 \times$ liver weight/body weight) were later calculated.

178

179 2.2. Broodstock feed

180

Previous studies have investigated dietary impacts on egg quality (Heinsbroek et al., 2013;

182 Støttrup et al., 2013, 2016). Based on these findings, fatty acid composition of the best performing

183 diet for females was used as basis for the fatty acid composition of these tested diets (hereafter

184 EH-4, EH-5, and EH-6). In terms of fatty acid composition, EH-4, EH-5, and EH-6 differed 
185 significantly from the commercial DAN-EX feed (Table 2). Amino acid composition varied 186 between all four diets, where the enhanced feeds were originally modified with respect to arginine 187 content (Table 1, Table 3). Here, arginine was lowest in EH-5 and highest in EH-6, while EH-4 188 showed intermediate levels.

189

\subsection{Amino acid analysis of milt}

191

Amino acid composition was analyzed using a EZ:fast ${ }^{\mathrm{TM}}$ amino acid analysis kit 193 (Phenomenex Inc., Torrance, CA, USA). Between $\sim 300$ to $2000 \mathrm{mg}$ of sperm samples were used 194 for the analysis depending on how much sample was available. Separation and detection of amino 195 acids occurred by liquid chromatography using Agilent G6120BA single-quadrupol LC-MS in the 196 ESI ionization mode (Agilent Technologies, Hørsholm, Denmark). The LC was equipped with an 197 EZ:fast ${ }^{\mathrm{TM}}$ Liquid chromatography-Mass spectroscopy (LC-MS) column $(250 \mathrm{~mm} \times 3.0 \mathrm{~mm}$, 198 Phenomenex). Amino acids were analyzed in duplicate or triplicate depending on milt volume. 199 Further details for amino acid analyses are described in Safafar et al. (2016).

200

201

\subsection{Milt production}

202

203

Males $(\mathrm{n}=97$ eels at start; $\mathrm{n}=27$ for DAN-EX; $\mathrm{n}=25$ for EH-4; $\mathrm{n}=25$ for EH-5; $\mathrm{n}=20$

204 for EH-6) were assessed weekly for spermiation one day after injection from Week 5 until Week

205 9. Fish ejaculate sperm spontaneously during natural spawning, but in captivity, it is typically 206 expressed from the sperm ducts by "stripping", where gentle abdominal pressure is applied. Thus, 207 slight pressure was applied to the abdomen of each male to assess their degree of maturity. Milt 
208 was then classified between $0-5$, where $0=$ no milt, $1=$ few drops with gentle pressure, $2=$ low

209 volume of milt with gentle pressure $(<0.5 \mathrm{~mL}), 3=$ medium volume of milt with gentle pressure

$210(<1.0 \mathrm{~mL}), 4=$ flowing milt with gentle pressure $(>1.0 \mathrm{~mL})$, and $5=$ freely flowing. Approximately

$21124 \mathrm{~h}$ after injection on Week 9, the total weight of milt per male was recorded and standardized

$212(\mathrm{~g} / 100 \mathrm{~g}$ eel $)$.

213

214

\subsection{Spermatozoa kinetic traits}

215

Milt samples from 83 males $(\mathrm{n}=22$ for DAN-EX; $\mathrm{n}=22$ for EH-4; $\mathrm{n}=20$ for EH-5; $\mathrm{n}=19$

217 for EH-6; one male was excluded from further analyses due to possible milt contamination) were

218 collected $24 \mathrm{~h}$ after the Week 9 injection, as the highest sperm quality is obtained at this time

219 (Pérez et al., 2000). Males were anesthetized with benzocaine $(60 \mathrm{mg} / \mathrm{L})$ to minimize any adverse

220 effects during stripping. The urogenital pore was cleaned with ionized water and wiped dry to

221 avoid contamination with feces, urine, or blood. To avoid any bias associated with time during

222 sampling, the milt was collected into weight boats from two males per diet, and this was repeated

223 until all males were sampled.

224 Immediately after stripping, a milt sample $(100 \mu \mathrm{L})$ from each male was diluted in $900 \mu \mathrm{L}$

225 of P1-extender medium (Peñaranda et al., 2010) and then kept in a cooler with frozen icepacks to

226 maintain viability. Before activation, the samples were inverted for $\sim 5 \mathrm{~s}$ for homogenization. The

227 immobilized sperm suspension $(0.2 \mu \mathrm{L})$ was then pipetted into a chamber of an $80 \mu \mathrm{m} 2 \mathrm{X}$-CEL

228 glass slide (Hamilton Thorne, MA, USA) and covered with a $22 \times 22 \mathrm{~mm}$ coverslip. The cells

229 were then activated with $15 \mu \mathrm{L}$ of modified seawater (36 ppt) with $1 \%$ bovine serum albumin,

230 BSA $(w / v)$. The BSA was added to the activation media as it prevents the sperm from sticking to 
231 the glass slide.

232 Sperm activity was captured at 10, 20, and $30 \mathrm{~s}( \pm 1)$ post-activation using a compound 233 microscope (Nikon Eclipse 55i microscope, Nikon Corporation, Tokyo, Japan) equipped with a

234 Nikon DS-Fil camera head and negative phase objective (PL 40 x /0.66, $\infty / 0.17)$. The digital video

235 camera was attached to a personal computer and images were captured using a frame grabber at

23650 frames/s (Procadi, PROiSER 1.4, Paterna, Spain). Three replicate activations were performed

237 for each male. Two observers continuously did all activations (752 video recordings) to avoid any

238 subjective deviation. Total motility (MOT, total number of motile spermatozoa/total number of

239 cells $\times 100)$ and curvilinear velocity (VCL, defined as velocity of sperm along its actual curvilinear

240 path) were then assessed using a computer-assisted sperm analysis (CASA; ISAS v1; PROiSER

241 R+D, S.L., Paterna, Spain).

242

243 2.6. Spermatocrit

244

245 Spermatocrit, defined as the ratio of packed sperm cells to the total volume of milt $\times 100$, 246 was used to estimate sperm concentration on Week 9 (Sørensen et al., 2013). For each male $(\mathrm{n}=$ 24784 eels), samples of milt were drawn into three microhematocrit capillary tubes (75 mm length 248 and 1.1-1.2 mm opening) and sealed at the end with Vitrex Sigillum wax. The tube was then 249 centrifuged for $10 \mathrm{~min}$ at $6000 \times \mathrm{g}$ (Haematokrit 210, Andreas Hettich GmbH \& Co. KG, 250 Tuttlingen, Germany) and the average of three replicate tubes was used for statistical analysis. 251 


\subsection{Histological analyses}

To assess testes development, testicular lobes were sampled after 9 weeks of hormonal

257 treatment from the middle of testes and preserved $(n=8$ per diet $)$ in a $4 \%$ solution of formalin 258 buffered by $\mathrm{NaH}_{2} \mathrm{PO}_{4}-\mathrm{H}_{2} \mathrm{O}$ and $\mathrm{Na}_{2} \mathrm{HPO}_{4}-2 \mathrm{H}_{2} \mathrm{O}$. Subsequently, the tissue samples were 259 dehydrated, embedded in paraffin, and sectioned at $5 \mu \mathrm{m}$. The sections were stained with 260 haematoxylin and eosin (H \& E, VWR-Bie \& Berntsen A/S, Denmark). The histological sections 261 were photographed (Olympus BX53 digital camera) at 200× magnification for identification of 262 gamete development stages and tissue, i.e. spermatogonia (Sg), spermatocytes (Sc), spermatids

$263(\mathrm{St})$, and spermatozoa (Sz). Testes tissues of five micrographs per male were categorized according

264 to gamete stages (i.e. $\mathrm{Sg}, \mathrm{Sc}, \mathrm{St}$, and $\mathrm{Sz}$ ) and their relative area fraction $(F)$ and progression of 265 spermatogenesis was assessed using a spermatogenic maturity index (SMI) (see Tomkiewicz et 266 al., 2011). SMI was estimated for each of the testes images in order to compare the morphological 267 development of the testes tissue in males receiving different amino acid diets $(\mathrm{n}=8-9$ fish per 268 diet).

\section{$270 \quad$ 2.8. Statistical analysis}

273 NC, USA) and R programming language (Venables and Ripley, 2002). Residuals were tested for 274 normality (Shapiro-Wilk test) and homogenous of variances (Levene's test). The significance level 275 was set at $\alpha=0.05$. Treatment means were determined using the honest significant difference 276 Tukey's test. Prior to or at the end of the experiment (Week 9), length, weight, liver weight, testes 
277 weight, GSI, and HSI were compared across the diets using a series of one-way ANOVAs. During

278 injections, eel body weights were compared using a repeated measures ANOVA model that 279 contained the factors: Time, Diet, and Time $\times$ Diet. One-way ANOVAs were used to compare 280 amino acids between the dietary groups. For statistical comparisons the amino acid composition 281 was compared as a percentage.

282 Logistic regression analysis was applied to estimate the parameters of a logistic model 283 consisting of a dependent variable (milt production) with two possible values, "unsuited" 284 (representing categories 0-2) or "suited" (categories 3-5) for further fertilization procedures (see 285 Section 2.4). In the logistic model, the log-odds for the value labeled "suited" is a linear 286 combination of two independent variables; a binary variable (diet) and a continuous variable 287 (time). The corresponding probability varied between 0 ("unsuited") and 1 ("suited"). At the end 288 of the experiment, the total weight of milt per male was recorded and standardized across the diets 289 using one-way ANOVA model.

290 Spermatocrit was compared across the diets with a one-way ANOVA model. A one-way 291 ANOVA model was also used to compare SMI between the diets on Week 9.Total motility and 292 curvilinear velocity were compared using a repeated measures ANOVA model that contained the 293 factors: Time (10, 20 and $30 \mathrm{~s})$, Diet, and Time $\times$ Diet.

294 Additionally, two principal components analyses (PCA) were performed to study the 1) 295 correlation between amino acid composition (in \% of total amino acids) in the diet and in the milt 296 samples, and 2) the correlation between amino acid composition (in \% of total amino acids) in the 297 milt samples and sperm motility and velocity. In both PCAs, the diets (DAN-EX, EH-4, EH-5, and 298 EH-6) were used as category variables. All parameters were weighted by $1 / \mathrm{SD}$ and full cross 299 validation was used. For the first PCA, the mean value for each amino acid in each diet was used 
300 for all milt samples receiving the same diet.

301

302

3. Results

303

304

3.1. Body morphometric measures

305

306

Prior to hormonal treatment, total body weight, length, and liver weight of eels ranged from

72 to $163 \mathrm{~g}, 34$ to $44 \mathrm{~cm}$, and 0.72 to $1.52 \mathrm{~g}$ respectively. There were no significant differences

308 detected between diets for these three morphometric traits $(\mathrm{P}>0.05)$.

309

For the hormonally treated males, total body weight ranged from 104 to $167 \mathrm{~g}$ for males fed

DAN-EX, 101 to $179 \mathrm{~g}$ for males fed EH-4, 100 to $150 \mathrm{~g}$ for males fed $\mathrm{EH}-5$, and 98 to $130 \mathrm{~g}$ for males fed EH-6. For the repeated measures ANOVA, the Time $\times$ Diet interaction and Time effect were both non-significant $(\mathrm{P}>0.05)$. On the contrary, dietary regime impacted total weight of the males $(\mathrm{P}<0.0001$; Fig. 1A), such that males fed EH-4 were the heaviest, while males fed EH-5

314 and EH-6 were the lightest (Fig. 1B).

315 At the end of the experiment (i.e. after Week 9 injection) liver weight, testes weight, GSI, 316 and HSI were compared across the diets. Here, liver weight and testes weight ranged from 1.04 to $317 \quad 1.09$ and 9.42 to $11.41 \mathrm{~g}$, respectively, and there were no significant differences between the diets 318 (P > 0.05). Additionally, GSI (ranged from 7.05 to 9.44) and HSI (ranged from 0.94 to 1.03) were 319 not significantly influenced by dietary regime $(\mathrm{P}>0.05)$. 
The amino acids detected in eel milt are displayed in Table 4. Arginine, alanine, and lysine

326 were the most abundant amino acids in eel milt (all $>11 \%$ ), followed by glycine, aspartic acid,

327 valine, glutamic acid, and leucine (all $>5.66 \%)$. Dietary regime significantly impacted arginine $(\mathrm{P}$

$328=0.01)$, serine $(\mathrm{P}<0.0001)$, proline $(\mathrm{P}=0.02)$, methionine $(\mathrm{P}=0.01)$, and histidine $(\mathrm{P}<0.0001)$

329 levels. Specifically, males fed DAN-EX, EH-4, and EH-5 had the highest percentages of arginine,

330 while males fed EH-4 to EH-6 had highest percentages of serine. Proline was most abundant in

331 males fed DAN-EX, EH-5, and EH-6. Both methionine and histidine were detected at low levels

$332(<2 \%)$, but were still impacted by dietary regime, where males fed EH-4 and EH-5 had the highest

333 percentages of methionine, and males fed DAN-EX, EH-4, and EH-6 had highest percentages of 334 histidine.

\subsection{Milt production and Spermatocrit}

Milt production was initially graded from 0 (no milt release) to 5 (flowing milt) and then 339 grouped as "unsuited" (categories 0-2) or "suited" (categories 3-5; Fig. 2A-F). Logistic regression

340 showed that milt production was significantly influenced by the time of hormonal treatment $(\mathrm{p}<$ $3410.001)$ and dietary regime $(p=0.020)$. Generally, milt production increased over time from almost 342 no milt on Week 5 to reach highest values on Week 9 , with $65 \%$ and $68 \%$ probability of milt 343 "suited" for fertilization procedures when males were fed EH-4 or EH-6 respectively, compared 344 to $18 \%$ or $28 \%$ when fed DAN-EX or EH-5, respectively (Fig A-F). Mean \pm SEM spermatocrit 345 for the males was $43.1 \pm 1.80 \%$ and it did not differ between the diets $(\mathrm{P}>0.05$, ranged from 
$34637.57 \%$ for males fed EH-6 to $47.21 \%$ for males fed EH-4; Fig. $2 \mathrm{G}$ ). The one-way ANOVA model

347 showed no impact of dietary regime on total milt weight, where it ranged from $1.91 \mathrm{~g} / 100 \mathrm{~g}$ eel

348 for males fed EH-6 to $2.32 \mathrm{~g} / 100 \mathrm{~g}$ eel for males fed EH-4 (P > 0.05; Fig. $2 \mathrm{H})$.

349

350

3.4. Spermatozoa kinetic traits

351

352

For sperm motility, the Time $\times$ Diet interaction $(\mathrm{P}>0.05$; Fig. $3 \mathrm{~A})$ and Time effect were

353 both non-significant $(\mathrm{P}>0.05)$. Dietary regime had an impact on sperm motility $(\mathrm{P}=0.007$; Fig.

354 3B), such that eels fed EH-5 or EH-6 had the greatest percentage of motile cells. The Time $\times$ Diet

355 interaction $(\mathrm{P}>0.05$; Fig. $3 \mathrm{C})$ and Time effect were also not significant for sperm velocity $(\mathrm{P}>$

356 0.05), while the dietary regime had an impact $(\mathrm{P}=0.003$; Fig. 3D). Here, fish fed the DAN-EX

357 diet or EH-5 and EH-6 had the fastest swimming sperm.

359 3.5. Histological analyses

360

361

The SMI of hormonally treated eels ranged from 0.54 to 0.80 after 9 weeks of hormonal

362 injections and did not differ between dietary treatment groups $(\mathrm{P}>0.05)$. All hormonally treated

363 males responded to treatment with testes showing progressed development, including

364 spermatocytes (Sc), spermatids (St) and spermatozoa (Sz) (Fig. 4). Sc and St dominated the least

365 developed males, but also tubules with attached developing Sz were observed (Fig. 4). In contrast,

366 free $\mathrm{Sz}$ in enlarged tubules dominated the most developed males, but still with prevalent Sc and

367 St. The continuous presence of $\mathrm{Sg}$ and $\mathrm{Sc}$ showed ongoing spermatogenesis in all males 368 independently of the diet they received (Fig. 4). 
3.6. Principal components analysis of amino acid composition in diet and milt samples

371

PCA was performed to study the correlation between the amino acid composition ( $\%$ of total

373 amino acids) in the diet and milt, where diets were used as category variables. From this PCA, it

374 was evident that three samples (two receiving EH-6 and one receiving EH-4) behaved as outliers.

375 A new PCA without these samples was therefore performed (Fig. 5A and B). PC1 and PC2

376 explained $43 \%$ and $15 \%$ of the variation in the data, respectively (Supplementary Table 1). Both

377 the scores and the loadings plot showed that PC1 explained the difference between the DAN-EX

378 diet/milt and the other samples, whereas PC2 mainly explained differences between EH-5 and EH-

3796 diet/milt. When taking these findings into consideration, the most interesting amino acids to

380 scrutinize further in the second PCA were proline, histidine and valine as well as lysine and

381 arginine (Fig. 5A and 5B). In Fig. 5B, proline, histidine and valine in the milt samples were located

382 close to EH-6 (in the first quadrant). These three amino acids in the diets (D-PRO, D-HIS, and D-

383 VAL) were all located to the far right indicating that the DAN-EX diet had a low content of these

384 three amino acids and that there was a positive correlation between the content of these amino

385 acids in the diet and in the milt samples. The same was also the case for glutamic acid and D-GLU,

386 which were both located to the left. Interestingly, lysine and arginine in the milt were located in

387 the $3^{\text {rd }}$ quadrant, whereas the variables for these two amino acids in the diet (D-LYS and D-ARG)

388 were located directly opposite in the $1^{\text {st }}$ quadrant, suggesting a negative correlation between the

389 presence of these amino acids in the diet and in the milt samples. The same was also the case for

390 other amino acids such as hydroxyproline (HYP to the left) and D-HYP (to the right) and for

391 phenylalanine (PHE to the right) and D-PHE (to the left). 
In order to study the correlation between sperm motility and amino acid composition (in \%

395 of total amino acids) a PCA including all samples and using diets as category variables was

396 performed. All samples excluding the three outliers mentioned above were used for the analysis

397 (Fig. 6A and B). PC1 and PC2 together explained $43 \%$ of the variation in the data (Supplementary

398 Table 2). The scores plot (Fig. 6A) showed that PC1 mainly explained differences between DAN-

399 EX samples to the left and the samples obtained from eel receiving the other diets (EH-4 to EH-

400 6), which were mainly located to the right. PC2 mainly explained differences between eels

401 receiving diet EH-4 in the top of the plot and EH-6 in the bottom of the plot. This interpretation of

402 the scores plot was also confirmed by the location of the diet category variables in the correlation

403 loadings plot (Fig. 6B). The correlation loadings plot showed a clear positive correlation between

404 motility parameters in the lower right corner and eel receiving diet EH-6. However, this

405 interpretation of the model was only partly confirmed by the original data in Figure 3, which did

406 not show a significant difference between EH-5 and EH-6. Further inspection of the scores plot in

407 Fig. 6A showed some overlap between the locations of the samples receiving different diets.

408 Particularly EH-4 and EH-5 samples were scattered in the plot. It was, however, clear that all

409 DAN-EX samples were located to the left in the scores plot and all EH-6 samples were located in

410 the lower part of the plot and mainly to the right. These findings thus suggest that eels fed EH-6

411 to a higher degree than eels fed DAN-EX had high motility sperm. Eels with high motility sperm

412 had milt with high relative proportions of proline, histidine and valine, but were particularly low

413 in lysine and arginine. They were also to some extent high in the amino acids located in the lower

414 part of the $1^{\text {st }}$ quadrant (threonine, isoleucine, serine, glycine). 


\section{Discussion}

In teleosts, studies have focused on amino acid requirements for growth and metabolism (Li

418 et al., 2009), however, their physiological significance in relation to reproduction and/or gamete

419 performance has not been well elucidated. Proteins and amino acids are the most abundant

420 constituents in fish gametes [e.g. free amino acids (FAAs) constitute up to $50 \%$ of the total amino

421 acid pool in marine pelagic fish eggs]. Here, they serve as an energy source during embryonic

422 development (Rønnestad et al., 1992; Syama Dayal et al., 2003), are important osmotic effectors

423 during oocyte hydration (Cerdà et al., 2007), and can even impact fertilization success (Kwasek et

424 al., 2014a). Moreover, dietary protein/amino acids modulate the time of puberty and rate of

425 maturation indirectly by impacting growth (Gunasekera et al., 1995). Therefore, dietary

426 supplementation of amino acids can provide quantitative evidence on whether the reproductive

427 performance or gamete quality in fish can be modified, particularly under captive conditions.

Amino acids or short peptides are produced as hydrolysates of intercellular matrix proteins,

429 to act as signals for maturation and timing of spermiation (Kawabata et al., 1992). In the present

430 study, diet did not influence organ-somatic indices (e.g. HSI, GSI) and testes histology, while it

431 impacted total weight of the males, where males fed EH-4 were the heaviest in comparison to other

432 groups. Moreover, induction of spermiation was significantly impacted by diet and time of 433 hormonal treatment, such that eels fed EH-4 and EH-6, on each week, showed the highest 434 probability of producing "suited" milt for further fertilization procedures, reaching values of $65 \%$ 435 and $68 \%$ on week 9 , respectively. This observation is in line with several other studies in which 436 certain amino acids positively impacted spermiation and male or female reproductive success. For 437 example, in ayu, Plecoglossus altivelis, additional tryptophan in the broodstock diet advanced the 
438 peak of serum testosterone levels and spermiation time in males and final maturation in females

439 (Akiyama et al., 1996). In the male rose bitterling Rhodeus ocellatus, Kawabata et al. (1992)

440 indicated that spermiation and sexual behavior was induced by several amino acids, such as

441 cysteine, serine, alanine, glycine, and lysine. In addition, supplementation of a diet with higher

442 levels of lysine significantly increased milt volume in silver catfish, Rhamdia voulezi (Diemer et

443 al., 2014), indicating relationships between levels of certain amino acids in the diet and 444 spermiation. Therefore, in the present study, it is quite likely that well-balanced amino acids or 445 specific amino acids in diets EH-4 and EH-6 were more favorable for European eel 446 spermatogenesis in comparison to the diets EH-5 and DAN-EX. Moreover, certain amino acids 447 (e.g. tyrosine, phenylalanine, glutamine, and leucine) are precursors for the synthesis and secretion 448 of hormones such as thyroid hormones, insulin hormones, growth hormones, prolactin, and 449 progesterone ( $\mathrm{Wu}, 2009)$. Presumably, in the present study, elevated levels of these hormones in 450 males fed EH-4 and EH-6 may have partly mediated induction of spermatogenesis, which warrants 451 further investigation also in relation to transmission of effects to offspring as these hormones play 452 a key role during early life development (Politis et al., 2017, 2018b, 2018c).

453 Sperm motility and velocity are regarded as primary determinants of reproductive success 454 and are commonly used to assess male gamete quality and fertilization potential (Gage et al., 2004; 455 Rurangwa et al., 2004; Gallego and Asturiano, 2018a,b; Zadmajid et al., 2019). Typically, sperm 456 with higher velocity and motility have the advantage of reaching the micropyle within a shorter 457 window of time during a fertilization event, while correlations have been found between sperm 458 motility parameters and fertilization rates in several fish species (reviewed by Gallego and 459 Asturiano, 2018a). Sperm motility parameters have been positively impacted by broodstock 460 nutrition for various fish species, such as barbel, Barbus barbus (Alavi et al., 2009), Senegalese 
461 sole, Solea senegalensis (Beirão et al., 2015), and European eel (Butts et al., 2015). Contrary to

462 fish, in mammals, the role of amino acids on sperm quality/function has received great attention.

463 For instance, incubation of goat sperm with specific amino acids (e.g. arginine), not only enhances

464 the $\mathrm{pH}$ and metabolic activity of sperm, but also the synthesis of ATP, which is essential for sperm

465 motility (Patel et al., 1998). In addition, supplementation of diets with amino acids improved sperm

466 motility and subsequent fertilization success in mice (Bahadorani et al., 2019), while for humans,

467 amino acid-deficient diets resulted in a $\sim 10$-fold increase in the percentage of non-motile sperm

468 (Wu et al., 2000). This striking observation underlines a critical role of amino acids for male 469 gamete performance.

470 We observed that dietary amino acids impacted sperm quality, where eels fed EH-5 or EH-

4716 presented an improvement in sperm motility parameters, which most likely increases chances

472 for sperm to achieve fertilization. The underlying mechanism(s) may be related to enhanced

473 synthesis of polyamines and amino acid-rich basic proteins in the sperm cells (Wu et al., 2009) or

474 activation of signaling molecules such as nitric oxide, which acts as a stimulator of sperm

475 motility/velocity (Creech et al., 1998; Barman et al., 2013). On the other hand, protein

476 phosphorylation processes, which trigger further cell signaling processes such as cyclic adenosine

477 monophosphate (cAMP) and hydrolysis of ATP catalyzed by dynein ATPase, are important

478 regulatory components for sperm swimming trajectories (Dzyuba and Cosson, 2014; Zilli et al., 479 2008,2017). Therefore, balanced amino acids in the diets EH-5 or EH-6 may have increased 480 intracellular ATP stores (Perchec Poupard et al., 1998), or changed the protein phosphorylation 481 state via production of proteins, which are involved in sperm motility activation, such as motor 482 proteins [e.g. A-kinase anchor protein (AKAP), axonemal dynein; Zilli et al., 2017], signaling 483 proteins [e.g. protein kinase A (PKA), Caspase 3, cleavage of PARP; Silva et al., 2015], and 
484 proteins involved in cell metabolism, including metabolism of reactive oxygen species (ROS) [e.g. 485 Acetyl-CoA synthetase, $\mathrm{Cu} / \mathrm{Zn}$ superoxide dismutase (Cu/Zn SOD); Zilli et al., 2017]. 486 Interestingly, in our study, PCA analysis showed that eels with high motility sperm had milt with 487 high relative proportions of proline, histidine, and valine, but were particularly low in lysine and 488 arginine. However, when comparing to other studies, the impact of amino acids on teleosts sperm 489 traits shows high species-specific variability. For example, in vitro incubation of rainbow trout, 490 Oncorhynchus mykiss spermatozoa with proline, isoleucine, and methionine had a positive effect 491 on sperm traits (e.g. motility, velocity and viability), while, proline, glutamine, cysteine, 492 asparagine, isoleucine, phenylalanine, serine, and histidine had a negative impact on common carp, 493 Cyprinus carpio sperm viability (Lahnsteiner, 2009). In both perch, Perca fluviatilis and gilthead 494 sea bream, Sparus aurata, glycine, lysine, methionine, and serine had a positive effect on sperm 495 motility in vitro (Lahnsteiner, 2010). In male yellow perch, Perca flavescens sperm motility and 496 fertilization rate were significantly decreased in the lysine deficient group (Kwasek et al., 2014a,b).

497 In addition, there is some evidence that in vitro supplementation of arginine with sperm cells 498 positively impacts sperm swimming behaviors in fish (Lahnsteiner, 2010), human (Keller and 499 Polakoski, 1975), rabbit (Radany and Atherton, 1981), and rat (Abd-Elrazek and Ahmed-Farid, 500 2018). The impact of amino acids on sperm motility and velocity has also been highlighted during 501 the freeze-thawing processes by protecting sperm cells against free-radical-induced damage 502 (Cabrita et al., 2011; Sangeeta et al., 2015). In ram semen, supplementation of freezing media with 503 proline led to a significant improvement in sperm motility, velocity, and structural and functional 504 integrity of biological membranes during the freezing and post-thawing process (Sangeeta et al., 505 2015). From the above reports, it clearly emerges that protein and amino acids are highly involved 506 in sperm motility initiation by different mechanisms, but with specific amino acid preference 
among species. Generally, it is not surprising that amino acids have species-specific impacts on

508 teleosts sperm performance, as amino acid composition and metabolism in general differs greatly

509 between fish.

510 In teleosts, it is well documented that dietary amino acid profiles are influencing post-

511 feeding levels of amino acids in the body, tissues, liver, and muscles (Kaushik et al., 1988; Mai et

512 al., 2006; Mozanzadeh et al., 2018). In addition, several authors have suggested that profiles of

513 amino acids present in the plasma are directly related to dietary composition. For example, dietary

514 supplementation of amino acids, enhanced the concentration of several amino acids in either blood

515 plasma or seminal plasma in different fish or mammal species (Tantikitti and March, 1995; Wu et

516 al., 2007; Dong et al., 2016). Nevertheless, relatively little information is available about the amino

517 acid composition of male germ cells and whether their accumulation impacts sperm functionality.

518 Available evidence shows that amino acid profiles in fish gametes are directly related to sperm

519 quality and fertilization success (He and Woods, 2003; Kwasek et al., 2014b). In support of this

520 notion, quantifying the free amino acid composition of sperm from several fish species revealed

521 that amino acids play a significant role in stimulation of sperm metabolic activity and viability,

522 and participates in various detoxifying functions (Lahnsteiner, 2009, 2010). Interestingly, in our

523 study, even on a quantitative basis, there was high accumulation ( $>35 \%$ of total) of arginine,

524 alanine, and lysine in milt, however, their incorporation at higher concentrations could not impact

525 sperm function in eel compared to other amino acids such as proline, histidine, and valine as

526 validated by PCA analysis. Similarly, previous studies on male European eel (Baeza et al., 2014,

527 2015a) reported that the specific use of every type of fatty acid depends on the tissue and phase of

528 spermatogenesis. Overall, the physiological roles of specific fatty acids and amino acids must be

529 clarified. In addition, the concentration of amino acids in male gonads or germ cells varies among 
530 and even within species, which makes it difficult to discern a particular pattern in amino acid

531 profiles. For example, methionine, arginine, and cysteine were found to be the main amino acids

532 in milt of rainbow trout (Lahnsteiner, 2009); leucine, arginine, glutamic acid, histidine, and lysine

533 in common carp, Cyprinus carpio (Lahnsteiner, 2009); arginine, alanine, isoleucine, tyrosine,

534 asparagine, methionine, tryptophan, glutamic acid, and lysine in perch (Lahnsteiner, 2010); and

535 leucine, arginine, methionine, glycine, hydroxyproline, cysteine, isoleucine, serine, glutamic acid,

536 lysine, phenylalanine, and asparagine in gilthead sea bream (Lahnsteiner, 2010). This variation is

537 largely due to differences in dietary protein sources (Forster and Ogata, 1998), diet formulation,

538 size, age of species, genetic differences, rearing conditions, and feeding practices (Ruchimat et al.,

539 1997). Furthermore, a considerable amount of amino acids are produced from the spermatic duct

540 epithelium (Lahnsteiner et al., 1993, 1994) or by proteolysis of seminal plasma (Ciereszko et al.,

541 1998), which could both change amino acid profiles in male gametes.

542 Overall, these findings not only add evidence that certain amino acids are essential for

543 regulating milt biochemistry, but also show that some ejaculate traits may be promoted by amino

544 acid intake (e.g. proline, histidine, and valine in the present study). Thus, further studies to evaluate

545 the effect of these supplemented diets on sperm fertilization ability and interlinked early

546 developmental stages (i.e., egg/embryo to early juveniles) are required. Moreover, new approaches

547 with high-throughput functional genomics, metabolomics, and proteomics may help to uncover

548 regulatory roles of these amino acids for gene and protein function. Thus, it would be interesting

549 to highlight these innovative methods in future attempts in order to expand our knowledge of

550 amino acid function for fish reproduction, especially for a critically endangered and economically

551 important catadromous fish species such as European eel. 


\section{Acknowledgements}

554

555 This study was funded by the Innovation Fund Denmark under grant agreements no. 5184-00093B

556 (EEL-HATCH) and 7076-00125B (ITS-EEL). Butts IAE, was also supported by the USDA

557 National Institute of Food and Agriculture, Hatch project 1013854. Gallego V has a post-doc grant

558 from the MICIU (Juan de la Cierva-Incorporación; IJCI-2017-34200).

559

560 References

561

562 Abd-Elrazek, A.M., Ahmed-Farid, O.A.H., 2018. Protective effect of L-carnitine and L-arginine 563 against busulfan-induced oligospermia in adult rat. Andrologia 50:e12806. 564 doi.org/10.1111/and.12806.

565 Akiyama, T., Shiraaishi, M., Yamamoto, T., Unuma, T., 1996. Effect of dietary tryptophan on 566 maturation of ayu Plecoglossus altivelis. Fish. Sci. 62, 776-782.

567 Alavi, S., Psenicka, M., Policar, T., Rodina, M., Hamackova, J., Kozak, P., Linhart, O., 2009.

568 Sperm quality in male Barbus barbus L. fed different diets during the spawning season. Fish 569 Physiol. Biochem. 35, 683-693.

570 Amirkhanov, G.A., 1980. Dynamics of free amino acids during the larval development of the 571 sevryuga, Acipenser stellatus. J. Ichthyol. 20, 116-121.

572 Asturiano, J.F., Sorbera, L.A., Carrillo, M., Zanuy, S., Ramos, J., Navarro, J.C., Bromage, N., 573 2001. Reproductive performance in male European sea bass (Dicentrarchus labrax, L.) fed 574 two PUFA enriched experimental diets: a comparison with males fed a wet diet. Aquaculture $575 \quad 194,173-190$. 
576 Asturiano, J.F., Pérez, L., Garzón, D.L., Peñaranda, D.S., Marco-Jiménez, F., Martínez-Llorens,

577 S., Tomás, A., Jover, M., 2005. Effect of different methods for the induction of spermiation

578 on semen quality in European eel. Aquacult. Res. 36, 1480-1487.

579 Baeza R., Mazzeo, I., Vílchez, M.C., Gallego, V., Peñaranda, D.S., Pérez, L., Asturiano, J.F., 2014.

580 Effect of thermal regime on fatty acid dynamics in male European eels (Anguilla anguilla)

581 during hormonally-induced spermatogenesis. Aquaculture 430, 86-97.

582 Baeza, R., Mazzeo, I., Vílchez, M.C., Gallego, V., Peñaranda, D.S., Pérez, L., Asturiano, J.F., 583 2015a. Relationship between sperm quality parameters and the fatty acid composition of the 584 muscle, liver and testis of European eel. Comp. Biochem. Physiol. A 181, 79-86.

585 Baeza R., Peñaranda, D.S., Vílchez, M.C., Tveiten, H., Pérez, L., Asturiano, J.F. 2015b. Exploring 586 correlations between sex steroids and fatty acids and their potential roles in the induced 587 maturation of the male European eel. Aquaculture 435, 328-338.

588 Bahadorani, M., Tavalaee, M., Abedpoor, N., Ghaedi, K., Nazem, M.N., Nasr-Esfahani, M.H., 589 2019. Effects of branched-chain amino acid supplementation and/or aerobic exercise on mouse sperm quality and testosterone production. Andrologia 51, e13183.

591 Beirão, J., Soares, F., Pousão-Ferreira, P., Diogo, P., Dias, J., Dinis, M.T., Herráez, M.P., Cabrita E., 2015. The effect of enriched diets on Solea senegalensis sperm quality. Aquaculture 435, 187-194.

595

Benini, E., Politis, S.N., Kottmann, J.S., Sørensen, S.R., Butts, I.A.E., Tomkiewicz, J., 2018. Effect of parental origin on early life history traits of European eel. Reprod. Domest. Anim. 53, 1149-1158. doi: 10.1111/rda.13219

Barman, A., Kumar, P., Mariahabib, K., Lal, B., 2013. Role of nitric oxide inmotility and fertilizing ability of sperm of Heteropneustes fossilis (Bloch.). Anim. Reprod. Sci. 137, 119-127. 
Bromage, N., Jones, J., Randall, C., Thrush, M., Davies, B., Sprinaget, J., Duston, J., Barker, G., 1992. Broodstock management, fecundity, egg quality and the timing of egg production in the rainbow trout (Oncorhynchus mykiss). Aquaculture 100, 141-166.

Buentello, J.A., Gatlin, D.M., 2001. Effects of elevated dietary arginine on resistance of channel catfish to exposure to Edwardsiella ictaluri. J. Aquat. Anim. Health 13, 194-201.

Butts, I.A.E., Baeza, R., Støttrup, J.G., Krüger-Johnsen, M., Jacobsen, C., Pérez, L., Asturiano, J.F., Tomkiewicz, J., 2015. Impact of dietary fatty acids on muscle composition, liver lipids, milt composition and sperm performance in European eel. Comp. Biochem. Physiol. A 183, $87-96$.

Cabrita, E., Ma, S., Diogo, P., Martínez-Páramo, S., Sarasquete, C., Dinis, M.T., 2011. The influence of certain aminoacids and vitamins on post-thaw fish sperm motility, viability and DNA fragmentation. Anim. Reprod. Sci. 125, 189-195.

Cabrita, E., Martínez-Páramo, S., Gavaia, P.J., Riesco, M.F., Valcarce, D.G., Sarasquete, C., Herráez, M.P., Robles, V., 2014. Factors enhancing fish sperm quality and emerging tools for sperm analysis. Aquaculture 432, 389-401.

Cerdà, J., Fabra, M., Raldúa, D., 2007. Physiological and molecular basis of fish oocyte hydration. In: Babin, P.J., Cerdà, J., Lubzens, E. (Eds.), The Fish Oocyte: From Basic Studies to Biotechnological Applications. Springer, Dordrecht, pp. 349-396.

Ciereszko, A., Piros, B., Dabrowski, K., Kucharczyk, D., Luczynski, M.J., Dobosz, S., Glogowski, J., 1998. Serine proteinase inhibitors of seminal plasma of teleost fish: distribution of activity, electrophoretic profiles and relation to proteinase inhibitors of blood. J. Fish Biol. $53,1292-1305$.

Creech, M.M., Arnold, E.V., Boyle, B., Muzinich, M.C., Montville, C., Bohle, D.S., Atherton, 
R.B., 1998. Sperm motility enhancement by nitric oxide produced by the oocytes of fathead minnows, Pimephales promelas. J. Androl. 19, 67-74.

624 Dabrowski, K., M. Luczynski, M., Rusiecki., 1985. Free amino acids in the late embryogenesis and pre-hatching stage of two coregonid fishes. Biochem. Syst. Ecol. 13, 349-356.

da Silva, F.F.G., Støttrup, J.G., Kjørsvik, E., Tveiten, H., Tomkiewicz, J., 2016. Interactive effects

of dietary composition and hormonal treatment on reproductive development of cultured females eel, Anguilla anguilla. Anim. Reprod. Sci. 171, 17-26.

da Silva, F.F.G., Jacobsen, C., Kjørsvik, E., Støttrup, J.G., Tomkiewicz, J., 2018. Oocyte and egg quality indicators in European eel: Lipid droplet coalescence and fatty acid composition. Aquaculture 496, 30-38.

Diemer, O., Bittencourt, F., Barcellos, L.G., Boscolo, W.R., Feiden, A., Romagosa, E., 2014. Lysine in the diet of Rhamdia voulezi male broodstocks confined in net cages. Aquaculture

Dong, H-J., Wu, D., Xu, S-Y., Li, Q., Fang, Z-F., Che, L-Q., Wu, C-M., Xu, X-Y., Lin, Y., 2016. Effect of dietary supplementation with aminoacids on boar sperm quality and fertility. Anim. Reprod. Sci. 172, 182-189.

Dzyuba, V., Cosson, J., 2014. Motility of fish spermatozoa: from external signaling to flagella response. Reprod. Biol. 14, 165-175.

Finn, R.N., Fyhn, H.J., 2010. Requirement for amino acids in ontogeny of fish. Aquacult. Res. 41, 684-716.

Forster, I., Ogata, H.Y., 1998. Lysine requirement of juvenile Japanese flounder Paralichthys olivaceus and juvenile red sea bream Pagrus major. Aquaculture 161, 131-142.

Gage, M.J.G., Macfarlane, C.P., Yeates, S., Ward, R.G., Searle, J.B., Parker, G.A., 2004. 
Spermatozoal traits and sperm competition in Atlantic salmon: relative sperm velocity is the primary determinant of fertilization success. Curr. Biol. 14, 44e7.

647 Gallego, V., Mazzeo, I., Vílchez, M.C., Peñaranda, D.S., Carneiro, P.C.F., Pérez, L., Asturiano, 648 J.F., 2012. Study of the effects of thermal regime and alternative hormonal treatments on the reproductive performance of European eel males (Anguilla anguilla) during induced sexual maturation. Aquaculture 354, 7-16.

651 Gallego, V., Asturiano, J.F., 2018a. Sperm motility in fish: technical applications and perspectives 652 through CASA-Mot systems. Reprod. Fertil. Develop. 30(6), 820-832.

653 Gallego, V., Asturiano, J.F., 2018b. Fish sperm motility assessment as a tool for aquaculture 654 research: a historical approach. Rev. Aquacult. (Published on-line). 28 pages. 655 https://doi.org/10.1111/raq.12253

656 Gunasekera, R. M., Shim, K.F., Lam, T.J., 1995. Effect of dietary protein level on puberty, oocyte 657 growth and egg chemical composition in the tilapia, Oreochromis niloticus (L.). Aquaculture $134,169-183$.

659 He, S., Woods III, L.C., 2003. Effects of glycine and alanine on short-term storage and 660 cryopreservation of Striped Bass (Morone saxatilis) spermatozoa. Cryobiology 46, 17-25.

661 Heinsbroek L., Støttrup J., Jacobsen C., Corraze G., Kraiem M., Holst L.K., Tomkiewicz J., 662 Kaushik S. 2013 A review on broodstock nutrition of marine pelagic spawners: The curious case of the freshwater eels (Anguilla spp.). Aquaculture Nutrition 19, 1-24.

664 Higuchi, M., Celino, F.T., Tamai, A., Miura, C., Miura, T., 2012. The synthesis and role of taurine 665 in the Japanese eel testis. Amino Acids 43, 773-781.

666 Izquierdo, M.S., Fernández-Palacios, H., Tacon, A.G.J., 2001. Effect of broodstock nutrition on 667 reproductive performance of fish. Aquaculture 197, 25-42. 
Jobgen W.S., Fried S.K., Fu W.J., Meininger C.J., Wu, G., 2006. Regulatory role for the argininenitric oxide pathway in metabolism of energy substrates. J. Nutr. Biochem. 17, 571-588.

670 Kaushik, S.J., Fauconneau, B., Terrier, L., Gras, J., 1988. Arginine requirement and status assessed by different biochemical indices in rainbow trout (Salmo gairdneri R.). Aquaculture 70,7595.

673 Kawabata, K., Tsubaki, K., Tazaki T., Ikeda, S., 1992. Sexual behavior induced by amino acids in 674 the Rose Bitterling Rhodeus ocellatus ocellatus. Nippon Suisan Gakk. 58, 839-844.

675 Keller, D.W., Polakoski, K.L., 1975. L-arginine stimulation of human sperm motility in vitro. Biol. Reprod. 13, 154-157.

677 Kjørsvik, E., Hoehne-Reitan, K., Reitan, K.I., 2003. Egg and larval quality criteria as predictive measures for juvenile production in turbot (Scophthalmus maximus L.). Aquaculture 227, 920.

Kwasek, K., Dabrowski, K., Nynca, J., Takata, R., Wojno, M., Wick, M., 2014a. The influence of

Kwasek, K., Dabrowski, K., Nynca, J., Wojno, M., Wick, M., 2014b. The influence of dietary dietary lysine on yellow perch female reproductive performance and the quality of eggs. N. Am. J. Aquac. 76, 351-358. lysine on yellow perch maturation and the quality of sperm. N. Am. J. Aquac. 76, 119-126.

Labbé, C., Maisse, G., Muller, K., Zachowski, A., Kaushik, S., Loir, M., 1995. Thermal acclimation and dietary lipids alter the composition, but not fluidity, of trout sperm plasmamembrane. Lipids 30, 23-33.

Lahnsteiner, F., Patzner, R.A., Weismann, T., 1993. The spermatic ducts of salmonid fishes (Salmonidae, Teleostei). Morphology, histochemistry and composition of the secretion. J. Fish Biol. 42, 79-93. 
691 Lahnsteiner, F., Patzner, R.A., Weismann, T., 1994. The testicular main ducts and spermatic ducts

692 in cyprinid fishes II. Composition of the seminal fluid. J. Fish Biol. 44, 459-467.

693 Lahnsteiner, F., 2009. The role of free amino acids in semen of rainbow trout Oncorhynchus mykiss

694 and carp Cyprinus carpio. J. Fish Biol. 75, 816-833.

695 Lahnsteiner, F., Mansour, N., McNiven, M., Richardson, G., 2009. Fatty acids of rainbow trout 696 (Oncorhynchus mykiss) semen: composition and effects on sperm functionality. Aquaculture 298, 118-124.

Lahnsteiner, F., 2010. A comparative study on the composition and importance of free amino acids in semen of gilthead sea bream, Sparus aurata, and perch, Perca fluviatilis. Fish Physiol. Biochem. 36, 1297-1305.

Li, P., Mai, K., Trushenski, J., Wu, G., 2009. New developments in fish amino acid nutrition: towards functional and environmentally oriented aquafeeds. Amino Acids 37, 43-53.

Mai, K., Zhang, L., Ai, Q., Duan, Q., Zhang, C., Li, H., Wan, J., Liufu, Z., 2006. Dietary lysine 704 requirement of juvenile seabass (Lateolabrax japonicus). Aquaculture 258, 535-542.

Mann, T., Lutwak-Mann, C., 1981. Biochemistry of seminal plasma and male accessory fluids; application to andrological problems. In: Mann, T., Lutwak-Mann, C. (Eds.). Male Reproductive Function and Semen. Springer-Verlag Berlin Heidelberg, New York, pp. 269-

Mansour, N., McNiven, M.A., Richardson, G.F., 2006. The effect of dietary supplementation with blueberry, alpha-tocopherol or astaxanthin on oxidative stability of Arctic char (Salvelinus alpinus) semen. Theriogenology 66, 373-382

Martinage, A., Gusse, M., Belaiche, D., Sautiere, P., Chevaillier, P., 1985. Amino acid sequence of a cysteine-rich, arginine-rich sperm protamine of the dog-fish Scylliorhinus caniculus. 
Biochim. Biophys. Acta 831, 172-178.

715 Matsunari, H., Hamada, K., Mushiake, K., Takeuchi, T., 2006. Effects of taurine levels in 716 broadstock diet on reprodutive performance of yellowtail Seriola quinqueradiata. Fish Sci. $717 \quad 71,955-960$.

718 Mozanzadeh, M.T., Yaghoubi, M., Marammazi, J.G., Safari, O., Gisbert, E., 2018. Effects of 719 dietary protein and essential amino acid deficiencies on growth, body composition, and 720 digestive enzyme activities of silvery-black porgy (Sparidentex hasta). Int. Aquat. Res. 10, $721 \quad 45-55$.

722 Mylonas, C.C., Duncan, N.J., Asturiano, J.F., 2017. Hormonal manipulations for the enhancement 723 of sperm production in cultured fish and evaluation of sperm quality. Aquaculture 472, 21$724 \quad 44$.

725 Nandi, S., Routray, P., Gupta, S.D., Rath, S.C., Dasgupta, S., Meher, P.K., Mukhopadhyay, P.K., 726 2007. Reproductive performance of carp, Catla catla (Ham.), reared on a formulated diet 727 with PUFA supplementation. J. Appl. Ichthyol. 23, 684-691.

728 Patel, A.B., Srivastava, S., Phadke, R.S., Govil, V., 1988. Arginine activates glycolysis of goat 729 epididymal spermatozoa: an NMR study. Biophys. J. 75, 1522-1528.

730 Peñaranda, D.S., Pérez, L., Gallego, V., Jover, M., Tveiten, H., Baloche, S., Dufour, S., Asturiano, 731 J.F., 2010. Molecular and physiological study of the artificial maturation process in 732 European eel males: from brain to testis. Gen. Comp. Endocrinol. 166, 160-171.

733 Perchec Poupard, G., Paxion, C., Cosson, J., Jeulin, C., Fierville, F., Billard, R., 1998. Initiation 734 of carp spermatozoa motility and early ATP reduction after milt contamination by urine. $735 \quad$ Aquaculture 160, 317-328.

736 Pérez, L., Asturiano, J.F., Tomás, A., Zegrari, S., Barrera, R., Espinós, F.J., Navarro, J.C., Jover, 
M., 2000. Induction of maturation and spermiation in the male European eel (Anguilla anguilla). Assessment of sperm quality throughout treatment. J. Fish Biol. 57, 1488-1504.

739

740

741

742

743

744

745

746

747

748

749

750

751

752

753

754

755

756

757

758

759

Politis, S. N., Mazurais, D., Servili, A., Zambonino-Infante, J.-L., Miest, J. J., Sørensen, S. R., Tomkiewicz, J., Butts, I.A.E., 2017. Temperature e $\square$ ects on gene expression and morphological development of European eel, Anguilla anguilla larvae. PLoS ONE 12(8): e0182726.

Politis, S.N., Mazurais, D., Servili, A., Zambonino-Infante, J.-L., Miest, J.J., Tomkiewicz, J., Butts, I.A.E., 2018a. Salinity reduction benefits European eel larvae: Insights at the morphological and molecular level. PLoS ONE 13(6): e0198294.

Politis, S.N., Servili, A., Mazurais, D., Zambonino-Infante, J.-L., Miest, J.J., Tomkiewicz, J., Butts, I.A.E., 2018b. Temperature induced variation in gene expression of the thyroid hormone pathway of European eel larvae. Gen. Comp. Endocrinol. 259, 54-65.

Politis, S.N., Sørensen, S.R., Mazurais, D., Servili, A., Zambonino-Infante, J.-L., Miest, J.J., Clemmesen, C.M., Tomkiewicz, J., Butts, I.A.E., 2018c. Molecular Ontogeny of FirstFeeding European Eel Larvae. Front. Physiol. 9:1477.

Pourkhazaei, F., Ebrahimi, E., Ghaedi, A., 2017. Arginine effects on biochemical composition of sperm in rainbow trout, Oncorhynchus mykiss. Aquac. Res. 48, 3464-3471.

Radany, E.W., Atherton, R.W., 1981. Arginine induced stimulation of rabbit sperm motility. Syst. Biol. Reprod. Med. 7, 351-355.

Rønnestad, I., Fyhn, H.J., Gravningen, K., 1992. The importance of free amino acids to the energy metabolism of eggs and larvae of turbot (Scophtalmus maximus). Mar. Biol. 114, 517-525.

Ruchimat, T., Masumoto, T., Hosokawa, H., Itoh, Y., Shimeno, S., 1997. Quantitative lysine requirement of yellowtail (Seriola quinqueradiata). Aquaculture 158, 331-339. 
760 Rurangwa, E., Kime, D.E., Ollevier, F., Nash, J.P., 2004. The measurement of sperm motility and 761 factors affecting sperm quality in cultured fish. Aquaculture 234, 1-28.

762 Safafar, H., Hass, M.Z., Møller, P., Holdt, S.L., Jacobsen, C., 2016. High-EPA Biomass from 763 Nannochloropsis salina cultivated in a flat-panel photo-bioreactor on a process water764 enriched growth medium. Mar. Drugs 14(8), 144.

765 Sangeeta, S., Arangasamy, A., Kulkarni, S., Selvaraju, S., 2015. Role of amino acids as additives 766 on sperm motility, plasma membrane integrity and lipid peroxidation levels at pre-freeze and 767 post-thawed ram semen, Anim. Reprod. Sci. 161, 82-88.

768 Silva, J.V., Freitas, M.J., Correia, B.R., Korrodi-Gregório, L., Patrício, A., Pelech, S., Fardilha, 769 M., 2015. Profiling signaling proteins in human spermatozoa: biomarker identification for 770 sperm quality evaluation. Fertil. Steril. 104(4), 845-856.e8.

771 Sørensen, S., Gallego, V., Pérez, L., Butts, I.A.E., Tomkiewicz, J., Asturiano, J.F., 2013. 772 Evaluation of methods to determine sperm density for the European eel, Anguilla anguilla. 773 Reprod. Dom. Anim. 48, 936-944.

774 Støttrup, J.G., Jacobsen, C., Tomkiewicz, J., Jarlbæk, H., 2013. Modification of essential fatty acid 775 composition in broodstock of cultured European eel Anguilla anguilla L. Aquacult. Nutr. $776 \quad 19,172-185$.

777 Støttrup, J.G, Tomkiewicz, J., Jacobsen, C., Butts, I.A.E., Holst, L., Krüger-Johnsen, M., Graver, 778 C., Lauesen, P., Fontagné-Dicharry, S., Heinsbroek, L., Corraze, G., Kaushik, S., 2016. 779 Development of a broodstock diet to improve developmental competence of embryos in $780 \quad$ European eel, Anguilla anguilla. Aquacult. Nutr. 22, 725-737.

781 Syama Dayal, J., Ahamad Ali, S., Thirunavukkarasu, A.R., Kailasam, M., Subburaj, R., 2003. 782 Nutrient and amino acid profiles of egg and larvae of Asian Seabass, Lates calcarifer 
(Bloch). Fish Physiol. Biochem. 29,141-147.

784 Tantikitti, C., March, B.E., 1995. Dynamics of plasma free amino acids in rainbow trout (Oncorhynchus mykiss) under variety of dietary conditions. Fish Physiol. Biochem. 13, 179194.

787 Tesch, F.-W. 2003. The eel, 5th edition. Blackwell Scientific Publications, Oxford, UK.

788 Tomkiewicz, J., Kofoed, T.M.N., Pederson, J.S., 2011. Assessment of testis development during 789 induced spermatogenesis in the European eel, Anguilla anguilla. Mar. Coast. Fish 3, 106-

Vassallo-Agius, R., Watanabe, T., Yoshizaki, G., Satoh, S., Takeuchi, Y., 2001. Quality of eggs and spermatozoa of rainbow trout fed an n-3 essential fatty acid-deficient diet and its effects

Venables, W.N., Ripley, B.D., 2002. Modern Applied Statistics with S-plus. New York: Springer-

Wu, G., Meininger, C.J., Knabe, D.A., Bazer, F.W., Rhoads, J.M., 2000. Arginine nutrition in development, health and disease. Curr. Opin. Clin. Nutr. Metab. Care 3, 59-66.

798 Wu, G., Bazer, F.W., Kim, S.W., 2007. New developments in amino acid research. In: Rosati, A., Tewolde, A., Mosconi, C. (Eds.) Animal Production and Animal Science Worldwide:

802 Wu, G., 2009. Amino acids: metabolism, functions, and nutrition. Amino Acids 37, 1-17.

803 Wu, G., Bazer, F.W., Davis, T.A., Kim, S.W., Li, P., Marc Rhoads, J., Satterfield, M.C., Smith, 804 805 WAAP Book of the Year 2006. Wageningen Academic Publishers, The Netherlands, pp. 299-315. S.B., Spencer, T.E., Yin, Y., 2009. Arginine metabolism and nutrition in growth, health and disease. Amino Acids 37, 153-168. 
806 Yao, K., Yin, Y.L., Chu, W., Liu, Z., Deng, D., Li, T., Huang, R., Zhang, J., Tan, B., Wang, W.,

807 Wu, G., 2008. Dietary arginine supplementation increases mTOR signaling activity in 808 skeletal muscle of neonatal pigs. J. Nutr. 138, 867-872.

809 Zadmajid, V., Myers, J.N., Sørensen, S.R., Butts, I.A.E. (2019). Ovarian fluid and its impacts on 810 sperm performance in fish: a review. Theriogenology 132, 144-152.

811 Zilli, L., Schiavone, R., Storelli, C., Vilella, S., 2008. Molecular mechanisms determining sperm 812 motility initiation in two sparids (Sparus aurata and Lithognathus mormyrus). Biol. Reprod. $813 \quad 79,356-366$.

814 Zilli, L., Schiavone, R., Vilella, S., 2017. Role of protein phosphorylation/dephosphorylation in 815 fish sperm motility activation: state of the art and perspectives. Aquaculture 472, 73-80. 
Fig. 1. Total weight of male European eel, Anguilla anguilla fed with four diets (DAN-EX, EH-4,

820 EH-5, EH-6). Box-and-whisker plot represent the diets for total weight of eels from Week 1 to

821 Week 9 (A) and the bar chart represents recorded total weight of fish between the diets (B). Values

822 with different subscripts differ $(\mathrm{P}<0.05)$. Results are expressed as mean values $\pm \mathrm{SEM}$.

823

824 Fig. 2. European eel males, Anguilla anguilla fed four diets (DAN-EX, EH-4, EH-5, EH-6) were

825 assessed for milt production from injection Week 5 until Week 9. Milt production was initially 826 graded from 0 (no milt release) to 5 (flowing milt) and then grouped as "unsuited" (categories 0-

827 2) or "suited" (categories 3-5; A-E). Regression analysis was then applied to estimate parameters

828 of a logistic model, where corresponding probabilities varied between 0 for "unsuited" and 1 for

829 "suited" milt for fertilization procedures (F). Spermatocrit (G) and standardized milt production [g $830 / 100 \mathrm{~g}$ eel, $(\mathrm{H})]$ for males fed the four diets was also determined. Values with different subscripts 831 are significantly different $(\mathrm{P}<0.05)$. Results are expressed as mean values $\pm \mathrm{SEM}$.

833 Fig. 3. Spermatozoa kinetic traits (A-D) of male European eel, Anguilla anguilla fed four diets

834 (DAN-EX, EH-4, EH-5, EH-6). For sperm motility and velocity, the Time $\times$ Diet interaction was 835 non-significant (A, C), therefore the Diet main effect was interpreted for each trait (B, D). Values 836 with different subscripts are significantly different $(\mathrm{P}<0.05)$. Results are expressed as mean values $837 \pm$ SEM

839 Fig. 4. Photomicrographs of histological sections of testes from selected male European eel, 840 Anguilla anguilla, in different developmental stages. Testis tissues were categorized according to 
841 prevalence of different cell types using the spermatogenic maturity index (SMI). Examples include

842 (A) SMI $=0.54$, male ID 39CD; (B) SMI $=0.56$, male ID 2CBC; (C) $\mathrm{SMI}=0.71$, male ID 7DE6;

843 (D) $\mathrm{SMI}=0.80$, male ID DCBA. Symbols indicate germ cells: $\mathrm{Sg}=$ spermatogonia; $\mathrm{Sc}=$

844 spermatocytes; $\mathrm{St}=$ spermatids; $\mathrm{Sz}=$ spermatozoa; as well as $\mathrm{Ad}=$ adipocytes.

846 Fig. 5. Score plot (A) and correlation loadings (B) from principal component analysis to study the 847 correlation between amino acid composition (in \% of total amino acids) in the diet and milt of

848 European eel, Anguilla anguilla. The diets (DAN-EX, EH-4, EH-5 and EH-6) were used as 849 category variables and the locations of the category variables are shown in the loadings plot. All 850 parameters were weighted by $1 / \mathrm{SD}$ and full cross validation was used. In the top panel (A), the 851 blue squares correspond to milt samples from fish receiving the DAN-EX diet, red circles to milt 852 from fish receiving the EH-4 diet, green triangles to milt from fish receiving the EH-5 diet, pink 853 diamonds to milt from fish receiving the EH-6 diet. The mean value for each amino acid in each 854 diet was used for all milt samples receiving the same diet. These amino acids are marked with "D" 855 before the amino acid to show that these are the values from the diets.

857 Fig. 6. Score plot (A) and correlation loadings (B) from principal component analysis to study the 858 correlation between amino acid composition (in \% of total amino acids) in milt samples, sperm 859 motility [MOT(10), MOT(20), and MOT(30)], and velocity [VLC(10) and VCL(20)] of European 860 eel, Anguilla anguilla. In the top panel (A), the blue squares correspond to milt samples from fish 861 receiving the DAN-EX diet, red circles to milt from fish receiving the EH-4 diet, green triangles 862 to milt from fish receiving the EH-5 diet, pink diamonds to milt from fish receiving the EH-6 diet. 863 The diets (DAN-EX, EH-4, EH-5 and EH-6) were used as category variables and the locations of 
864 the category variables are shown in the loadings plot. All parameters were weighted by $1 / \mathrm{SD}$ and

865 full cross validation was used.

867 Table captions:

Table 1. Dietary formulation for the "enhanced" feeds (EH-4, EH-5, EH-6) that were fed to male

871 European eel, Anguilla anguilla.

872

873 Table 2. Composition of fatty acids in the diets $(\mathrm{EH}-4, \mathrm{EH}-5, \mathrm{EH}-6, \mathrm{n}=2$ samples analyzed per 874 diet) that were fed to male European eel, Anguilla anguilla. The commercial feed was DAN-EX $8752848(\mathrm{n}=2$ samples analyzed). Diets are presented as average ( $\%$ of total fatty acids in the feed) $876 \pm$ standard deviation (SD).

877

878 Table 3. Composition of amino acids in the diets (EH-4, EH-5, EH-6; $n=3$ samples analyzed per 879 diet) that were fed to male European eel, Anguilla anguilla. The commercial feed was DAN-EX $8802848(\mathrm{n}=2$ samples analyzed). Diets are presented as average ( $\%$ of total amino acids in the feed) $881 \pm$ standard deviation (SD).

882

883 Table 4. Composition of amino acids (percentage of total amino acids) in milt of male European 884 eel, Anguilla anguilla fed different diets (EH-4, EH-5, EH-6, DAN-EX). Commercial feed used 885 was DAN-EX 2848. Results are presented as average ( $\%$ of total amino acids in the feed) \pm 886 standard deviation $(\mathrm{SEM})$. Small letters show significant differences $(\mathrm{P}<0.05)$ in each amino acid 887 over the dietary regimes. 
Fig. 1
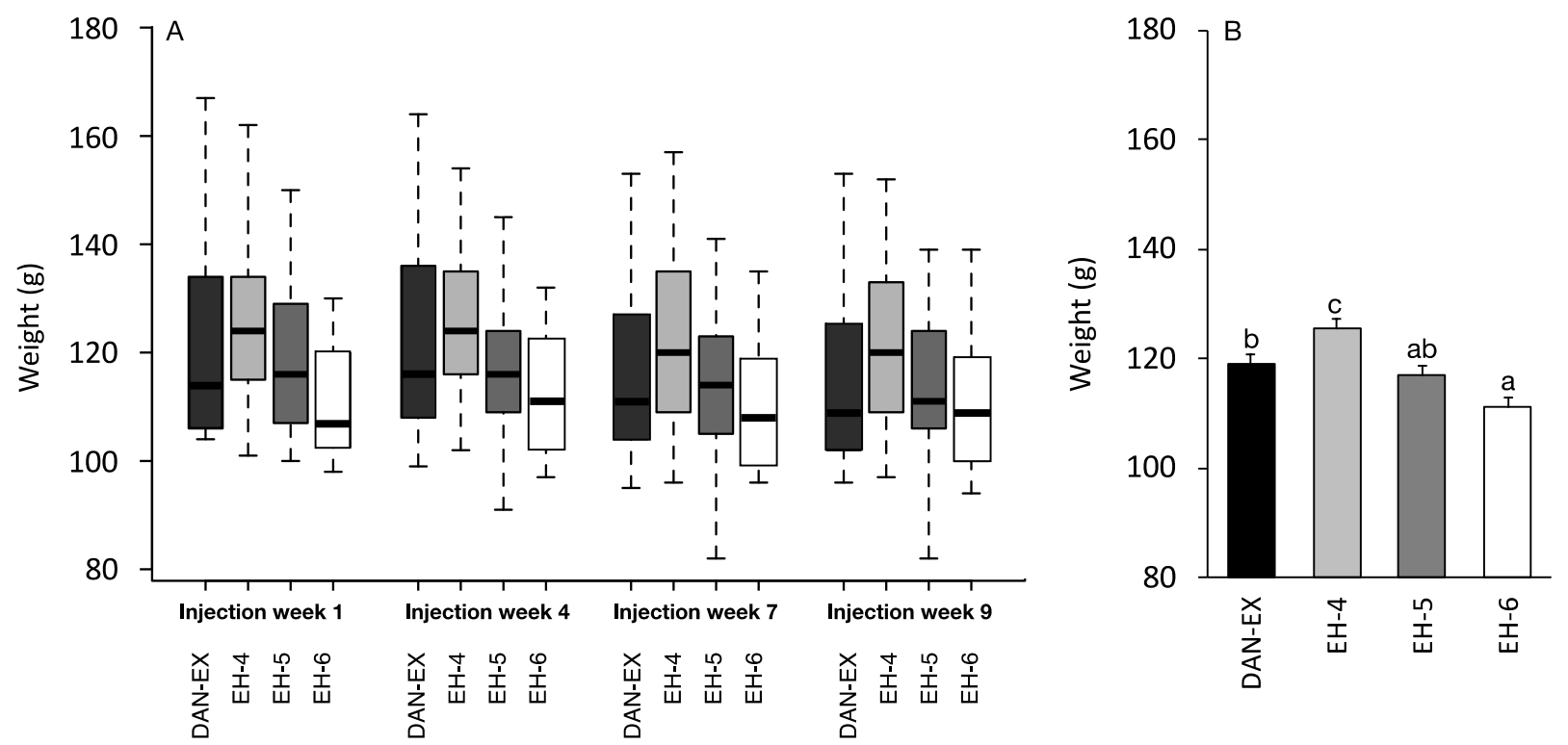
Fig. 2
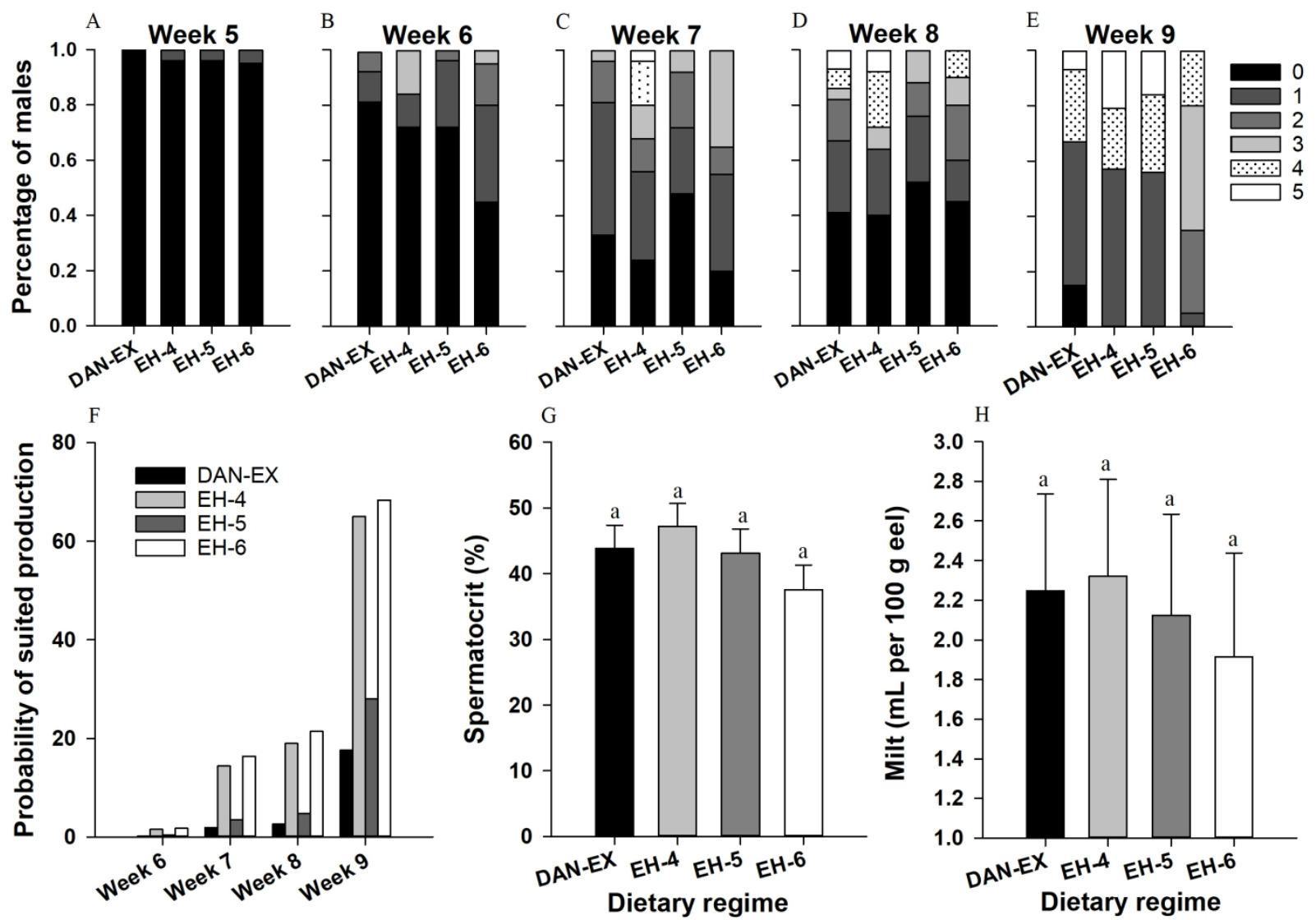
Fig. 3
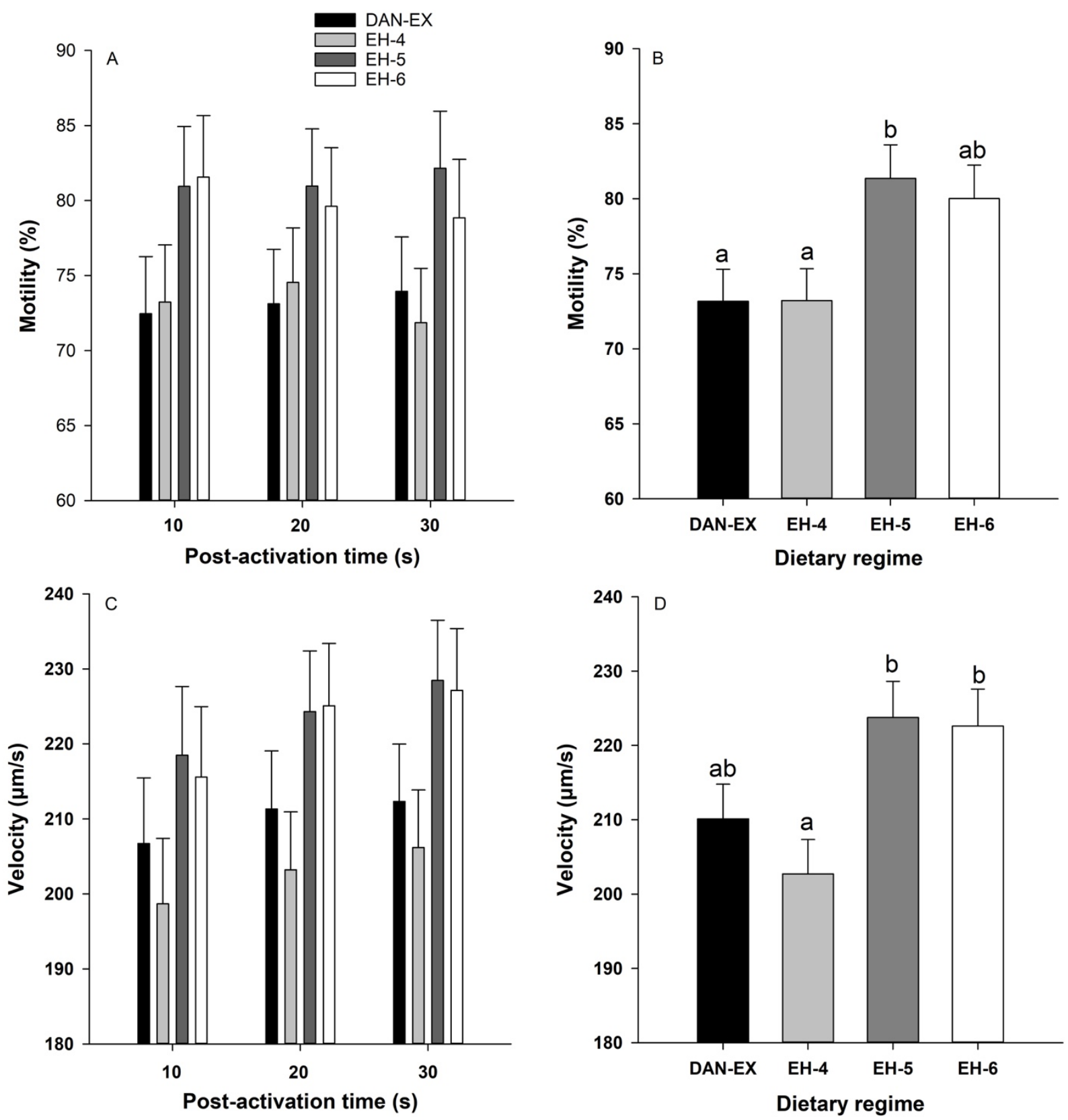


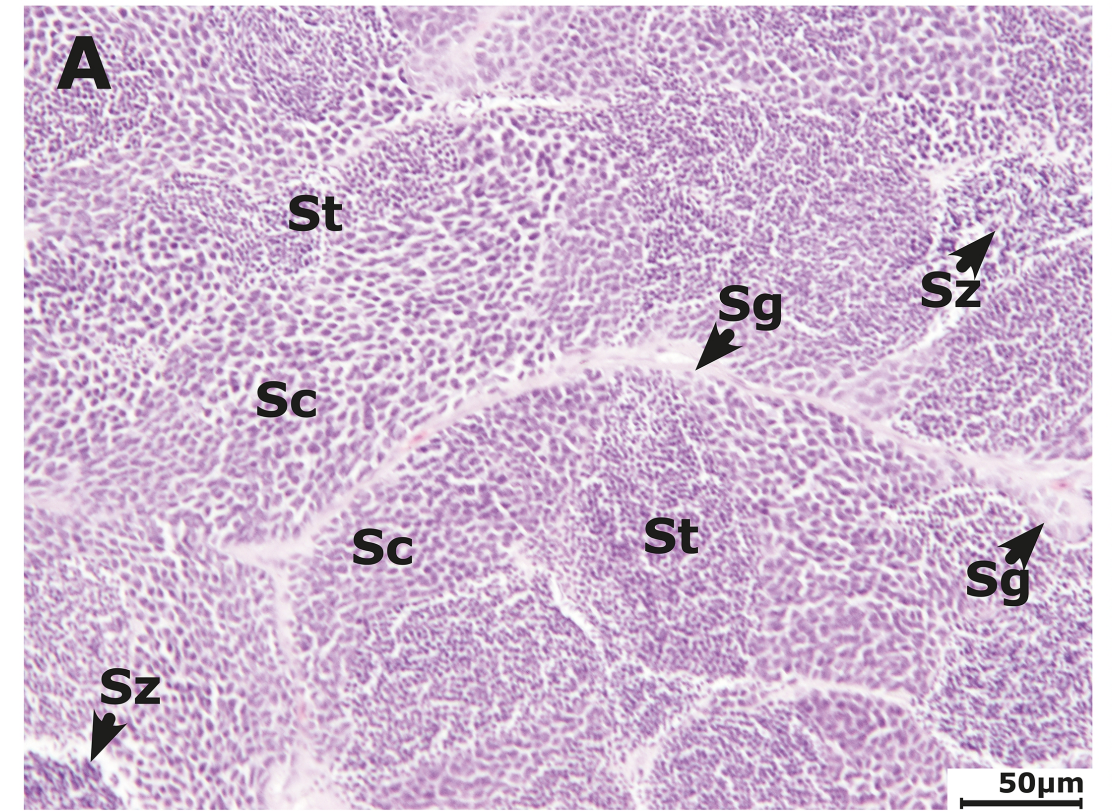

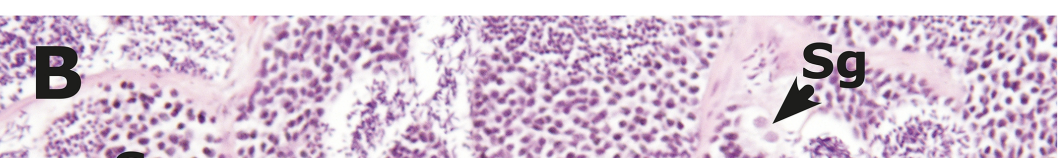

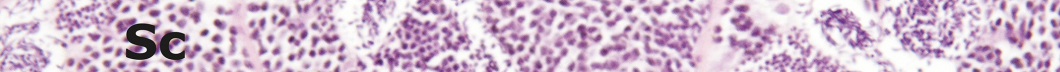

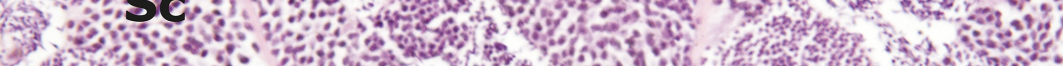

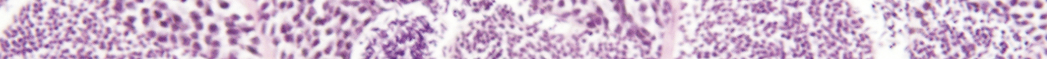
ct

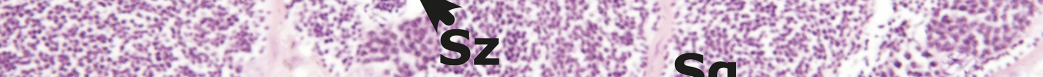

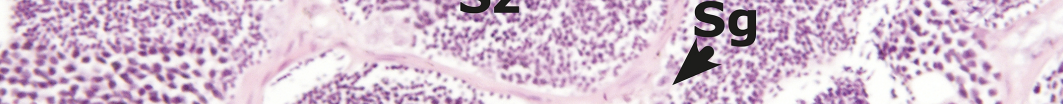

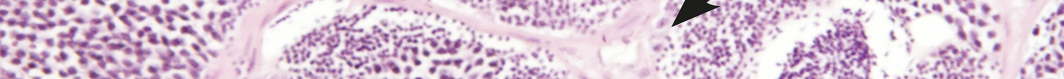

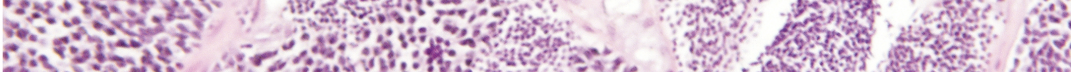
15.0.

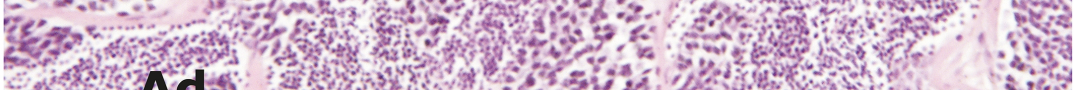

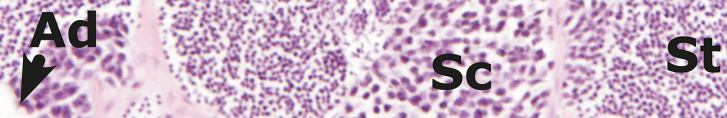

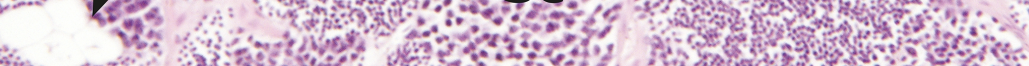

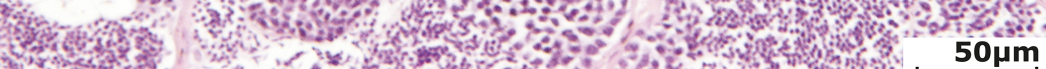

Cow

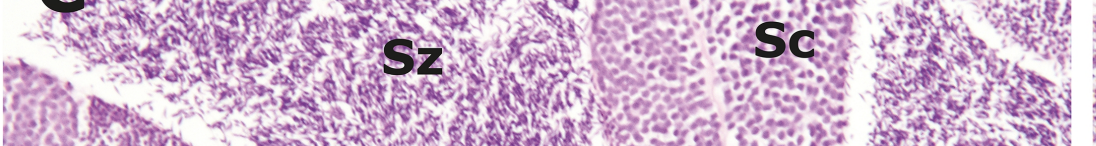

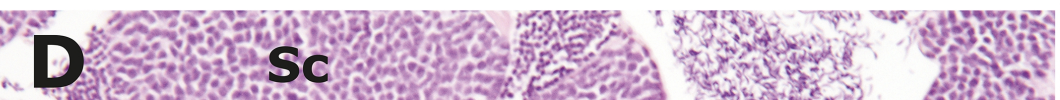
15 we w

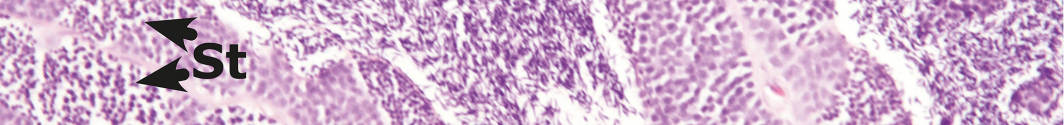

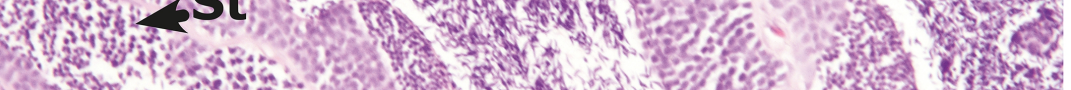

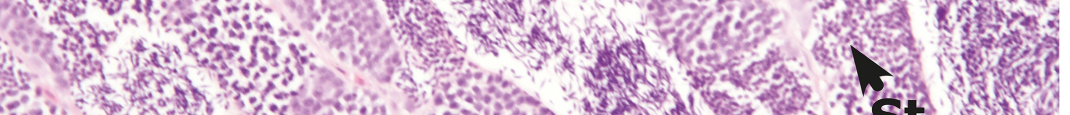
(1)

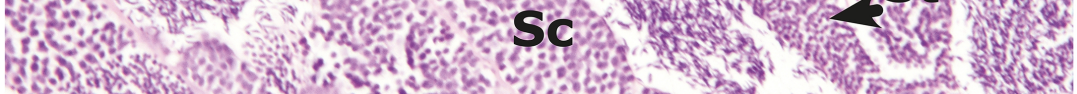
\%

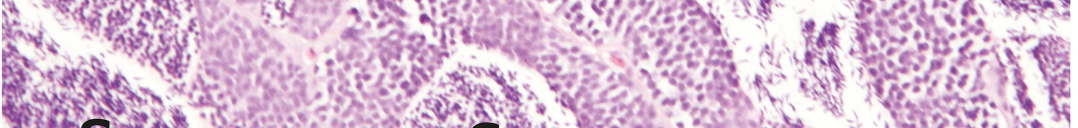

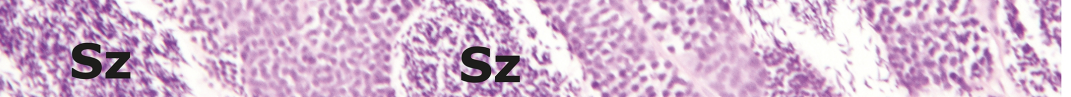

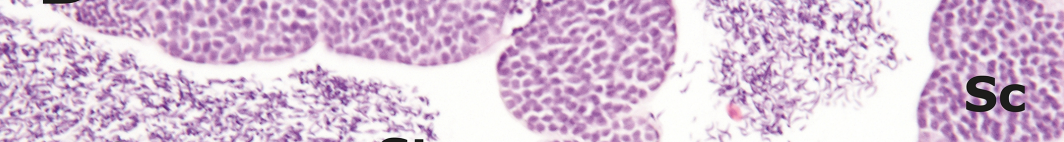

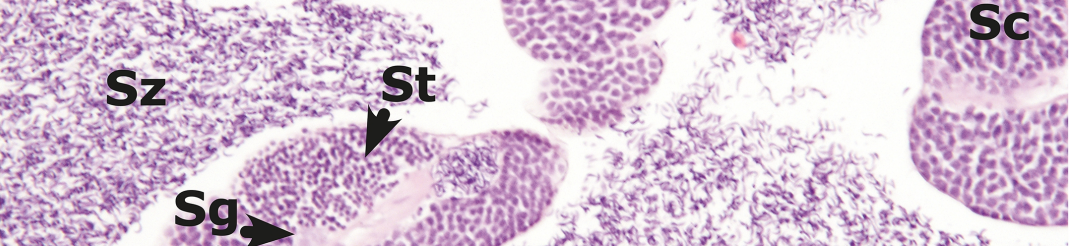
32 .

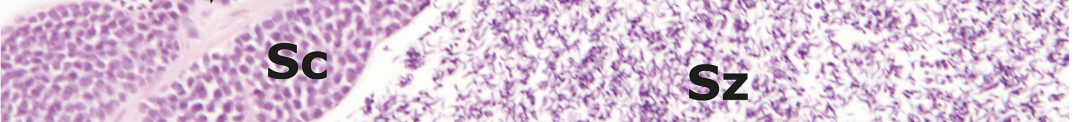

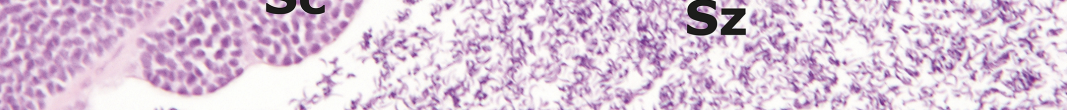
(4)

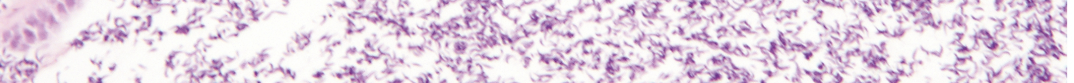
H. 1 . 20 
Fig. 5

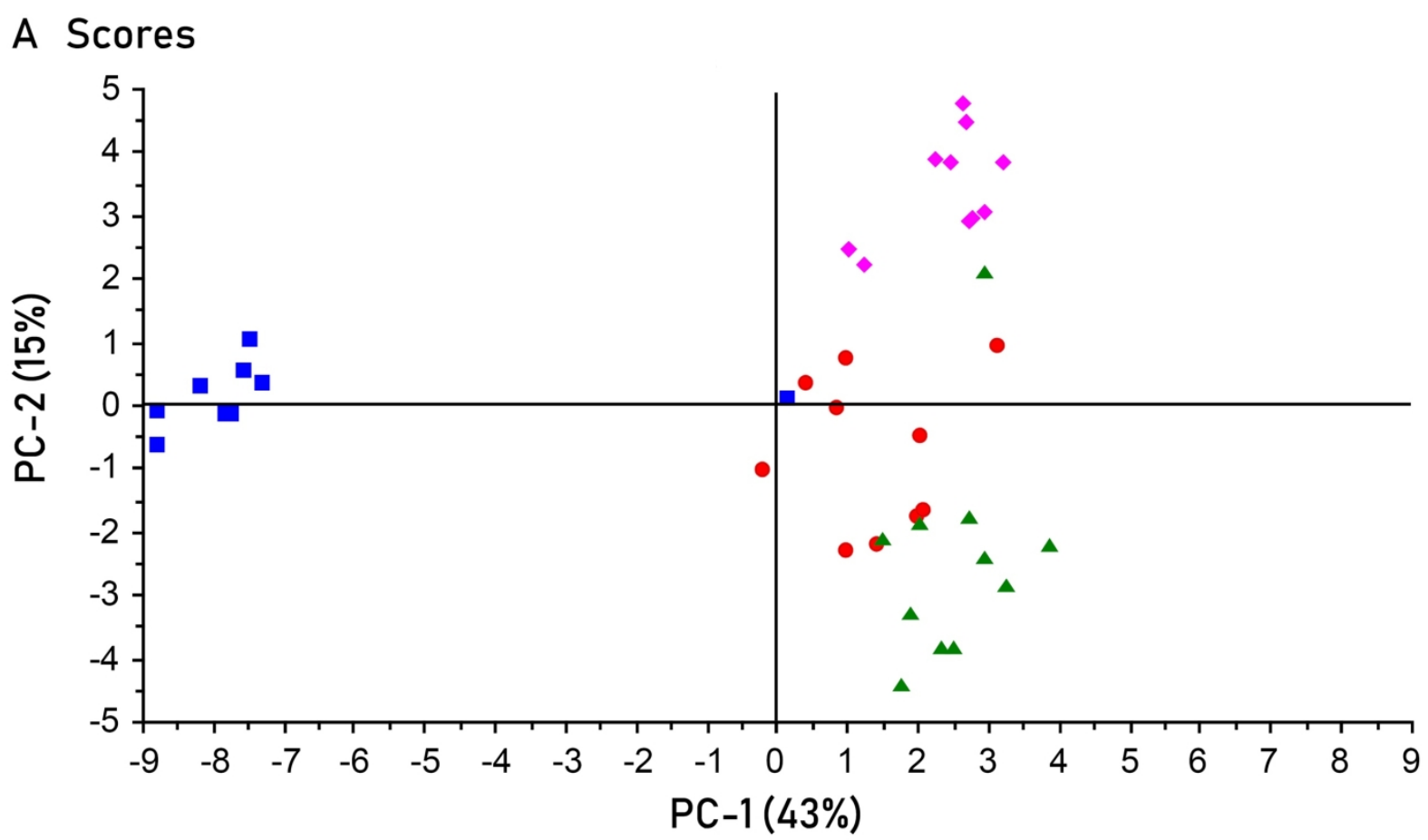

B Correlation Loadings ( $\mathrm{X}$ )

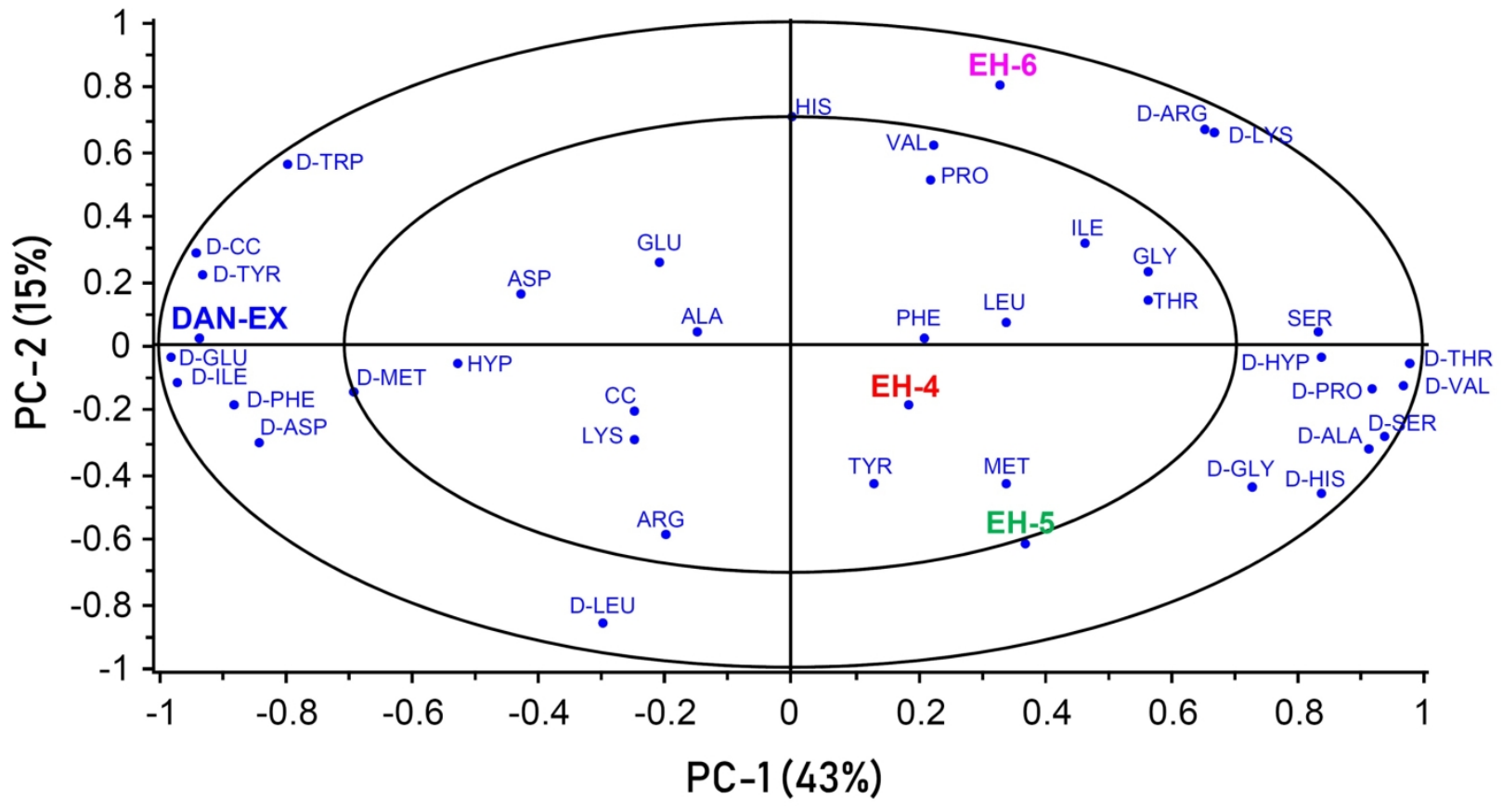


Fig. 6

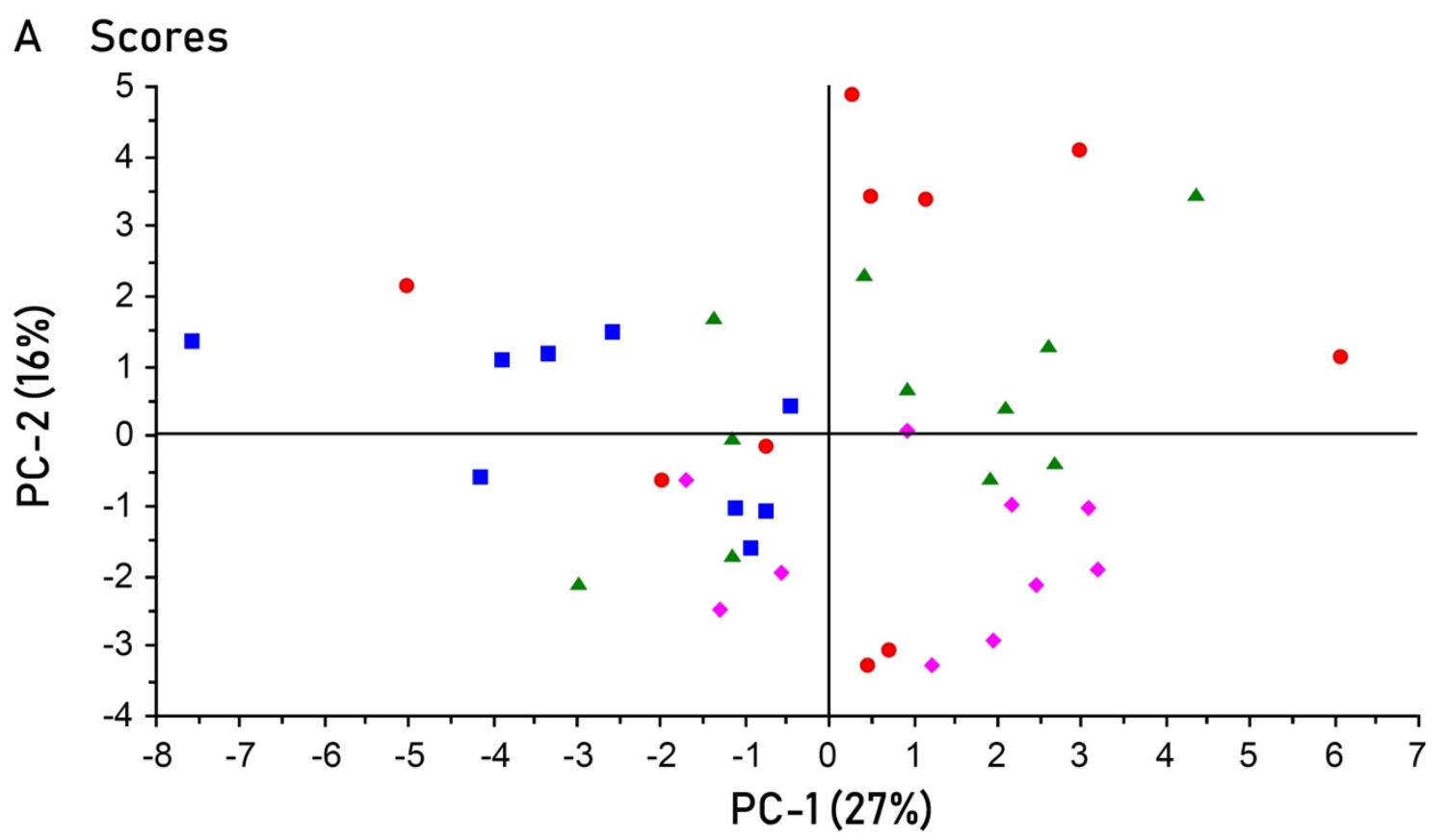

B Correlation Loadings $(X)$

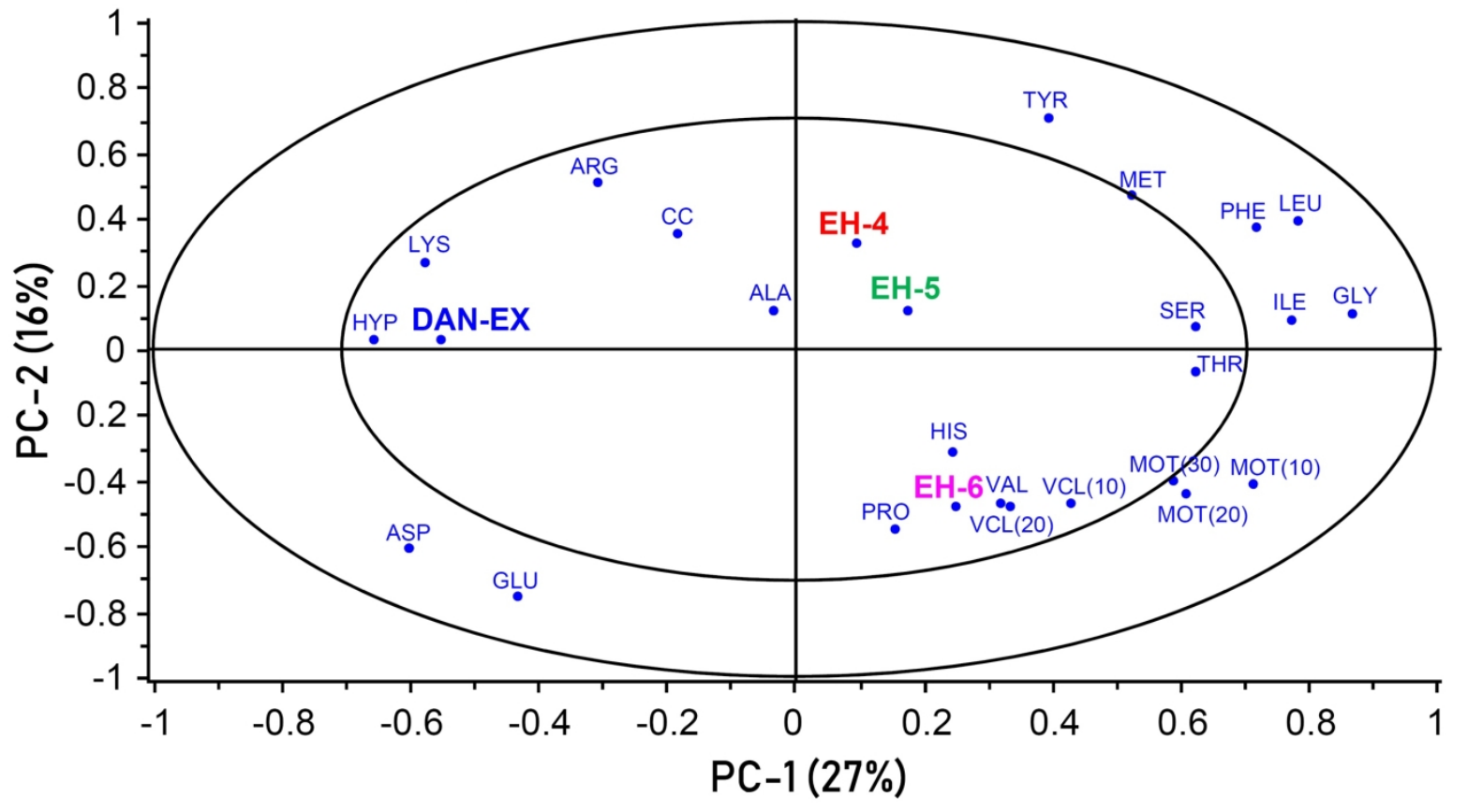


Table 1

\begin{tabular}{lccc}
\hline Dietary formulation & EH-4 & EH-5 & EH-6 \\
\hline Fish Meal LT & 53.275 & 55.136 & 53.727 \\
Wheat Gluten & 9 & 9 & 9 \\
Wheat & 22 & 20 & 20 \\
Fish Oil & 6.03 & 5.79 & 5.95 \\
Rapeseed Oil & 5 & 5 & 5 \\
Vevodar & 2.35 & 2.39 & 2.37 \\
Premix & 2.03 & 1.82 & 1.93 \\
L-Lysine HCI (78\%) &. & 0.17 & 0.28 \\
DL-Methionine (99\%) & 0.22 & 0.19 & 0.22 \\
L-Threonine (98\%) &. & 0.19 & 0.23 \\
L-Histidine (74\%) &. &. & 0.03 \\
Water change & -3.423 & -3.204 & -3.083 \\
Lecithin, liquid & 0.5 & 0.5 & 0.5 \\
DHA Liqiud & 3 & 3 & 3 \\
L-argenin &. &. & 0.828 \\
Total & 100 & 100 & 100 \\
Moisture (\%) & & & \\
Protein - crude (\%) & 5.47 & 5.528 & 5.529 \\
Fat - crude (\%) & 48.29 & 49.783 & 49.802 \\
Ash (\%) & 23.032 & 22.979 & 22.976 \\
Cellulose - crude (\%) & 8.061 & 8.065 & 7.992 \\
Crude fiber (\%) & 0.579 & 0.535 & 0.535 \\
\hline
\end{tabular}


Table 2.

\begin{tabular}{|c|c|c|c|c|c|c|c|c|}
\hline \multirow{2}{*}{$\begin{array}{l}\text { Fatty } \\
\text { Acids }\end{array}$} & \multicolumn{2}{|c|}{$\begin{array}{c}\text { DAN-EX } \\
(n=2)\end{array}$} & \multicolumn{2}{|c|}{$\begin{array}{l}\text { EH-4 } \\
(n=2)\end{array}$} & \multicolumn{2}{|c|}{$\begin{array}{l}\text { EH-5 } \\
(n=2)\end{array}$} & \multicolumn{2}{|c|}{$\begin{array}{l}\text { EH-6 } \\
(n=2)\end{array}$} \\
\hline & Mean & SD & Mean & SD & Mean & SD & MEAN & SD \\
\hline C14:00 & 5.19 & 0.01 & 3.44 & 0.04 & 3.39 & 0.02 & 3.48 & 0.01 \\
\hline C16:00 & 10.79 & 0.02 & 11.77 & 0.04 & 11.72 & 0.03 & 11.85 & 0.04 \\
\hline C16:1(n-7) & 7.35 & 0.01 & 4.31 & 0.02 & 4.16 & 0.03 & 4.22 & 0.02 \\
\hline C18:00 & 1.32 & 0.03 & 3.04 & 0.03 & 3.22 & 0.00 & 3.15 & 0.06 \\
\hline C18:1(n-9) & 16.07 & 0.02 & 19.28 & 0.19 & 19.02 & 0.12 & 19.02 & 0.03 \\
\hline C18:1(n-7) & 2.71 & 0.01 & 2.00 & 0.02 & 2.14 & 0.00 & 2.13 & 0.04 \\
\hline$C 18: 2(n-6)$ & 6.02 & 0.04 & 12.90 & 0.13 & 12.91 & 0.05 & 13.00 & 0.04 \\
\hline C18:3(n-3) & 1.62 & 0.01 & 1.05 & 0.02 & 1.11 & 0.05 & 1.06 & 0.00 \\
\hline C20:1(n-7) & 0.74 & 0.00 & 0.37 & 0.00 & 0.38 & 0.01 & 0.38 & 0.00 \\
\hline$C 20: 4(n-6)$ & 0.28 & 0.00 & 4.33 & 0.04 & 4.41 & 0.04 & 4.39 & 0.02 \\
\hline$C 20: 5(n-3)$ & 5.49 & 0.02 & 3.90 & 0.05 & 3.96 & 0.02 & $4.01 \pm$ & 0.02 \\
\hline$C 22: 1(n-11)$ & 13.36 & 0.03 & 8.29 & 0.08 & 8.13 & 0.04 & 8.30 & 0.05 \\
\hline$C 22: 5(n-3)$ & 0.49 & 0.00 & 0.56 & 0.00 & 0.56 & 0.00 & 0.57 & 0.00 \\
\hline$C 22: 6(n-3)$ & 5.32 & 0.04 & 6.61 & 0.09 & 6.79 & 0.02 & 6.91 & 0.02 \\
\hline total $n-3$ & 14.07 & 0.12 & 13.01 & 0.10 & 13.33 & 0.12 & 13.59 & 0.22 \\
\hline total $n-6$ & 6.74 & 0.05 & 17.96 & 0.17 & 18.12 & 0.17 & 18.13 & 0.07 \\
\hline$n-3 / n-6$ & 2.09 & & 0.72 & & 0.74 & & 0.75 & \\
\hline total SFA & 17.98 & 0.07 & 19.18 & 0.23 & 19.18 & 0.07 & 19.34 & 0.13 \\
\hline total MUFA & 54.22 & 0.16 & 42.64 & 0.39 & 42.41 & 0.33 & 42.66 & 0.20 \\
\hline total PUFA & 23.74 & 0.20 & 34.44 & 0.53 & 35.24 & 0.49 & 35.29 & 0.30 \\
\hline
\end{tabular}


Table 3.

\begin{tabular}{|c|c|c|c|c|c|c|c|c|}
\hline \multirow{2}{*}{$\begin{array}{l}\text { Amino } \\
\text { Acids }\end{array}$} & \multicolumn{2}{|c|}{ DAN-EX $(n=2)$} & \multicolumn{2}{|c|}{ EH-4 $(n=3)$} & \multicolumn{2}{|c|}{ EH-5 $(n=3)$} & \multicolumn{2}{|c|}{ EH-6 $(n=3)$} \\
\hline & Mean & SD & Mean & SD & Mean & SD & MEAN & SD \\
\hline Alanine & 4.47 & 0.01 & 7.01 & 0.66 & 7.21 & 1.04 & 6.37 & 0.70 \\
\hline Arginine & 4.83 & 0.28 & 7.20 & 0.11 & 6.42 & 1.71 & 10.26 & 1.29 \\
\hline Aspartic acid & 11.27 & 0.52 & 10.02 & 1.07 & 8.91 & 0.37 & 8.02 & 1.15 \\
\hline Cysteine & 0.96 & 0.04 & 0.72 & 0.04 & 0.67 & 0.08 & 0.75 & 0.09 \\
\hline Glutamic acid & 30.22 & 0.12 & 20.38 & 2.40 & 19.71 & 2.10 & 18.91 & 1.28 \\
\hline Glycine & 4.79 & . & 5.23 & 0.53 & 6.15 & 0.67 & 5.43 & 0.35 \\
\hline Histidine & 1.54 & 0.01 & 1.81 & 0.31 & 2.00 & 0.36 & 1.78 & 0.39 \\
\hline Hydroxyproline & 0.64 & 0.04 & 0.93 & 0.03 & 1.00 & 0.06 & 0.98 & 0.10 \\
\hline Isoleucine & 3.80 & 0.23 & 3.08 & 0.10 & 2.93 & 0.37 & 2.80 & 0.32 \\
\hline Leucine & 6.97 & 0.04 & 6.92 & 0.79 & 7.03 & 0.73 & 6.57 & 0.63 \\
\hline Lysine & 7.13 & 0.18 & 8.08 & 0.59 & 7.81 & 1.88 & 9.30 & 1.45 \\
\hline Methionine & 3.56 & 0.21 & 3.03 & 0.43 & 3.35 & 0.25 & 3.20 & 0.40 \\
\hline Phenylalanine & 5.22 & 0.17 & 4.17 & 0.72 & 4.53 & 0.56 & 4.23 & 0.62 \\
\hline Proline & 0.34 & 0.03 & 5.06 & 0.07 & 5.27 & 0.48 & 4.79 & 0.17 \\
\hline Serine & 3.64 & 0.10 & 4.47 & 0.21 & 4.77 & 0.26 & 4.45 & 0.24 \\
\hline Threonine & 2.99 & 0.13 & 3.35 & 0.05 & 3.96 & 0.35 & 3.85 & 0.13 \\
\hline Tryptophan & 0.32 & 0.01 & 0.27 & 0.02 & 0.25 & 0.05 & 0.29 & 0.07 \\
\hline Tyrosine & 3.43 & 0.22 & 2.65 & 0.11 & 2.69 & 0.23 & 2.83 & 0.22 \\
\hline Valine & 3.87 & 0.01 & 5.61 & 0.29 & 5.33 & 1.14 & 5.20 & 0.67 \\
\hline
\end{tabular}


Table 4.

\begin{tabular}{|c|c|c|c|c|c|c|c|c|c|}
\hline \multirow{2}{*}{$\begin{array}{l}\text { Amino } \\
\text { Acids }\end{array}$} & \multicolumn{2}{|c|}{ DAN-EX } & \multicolumn{2}{|c|}{ EH-4 } & \multicolumn{2}{|c|}{ EH-5 } & \multicolumn{2}{|c|}{ EH-6 } & \multirow{2}{*}{ P-value } \\
\hline & Mean & SEM & Mean & SEM & Mean & SEM & MEAN & SEM & \\
\hline Alanine & 11.54 & 1.20 & 13.30 & 1.09 & 10.65 & 1.09 & 13.02 & 1.04 & 0.28 \\
\hline Arginine & $12.83^{b}$ & 0.75 & $11.51^{\mathrm{ab}}$ & 0.68 & $13.00^{\mathrm{b}}$ & 0.68 & $10.12^{\mathrm{a}}$ & 0.65 & 0.01 \\
\hline Aspartic acid & 6.91 & 0.45 & 5.76 & 0.40 & 6.09 & 0.40 & 6.59 & 0.39 & 0.23 \\
\hline $\mathrm{C}-\mathrm{C}$ & 0.81 & 0.06 & 0.79 & 0.06 & 0.77 & 0.06 & 0.85 & 0.05 & 0.75 \\
\hline Glutamic acid & 8.29 & 0.63 & 7.42 & 0.57 & 7.67 & 0.57 & 8.87 & 0.55 & 0.28 \\
\hline Glycine & 5.66 & 0.21 & 6.13 & 0.19 & 6.21 & 0.19 & 6.17 & 0.18 & 0.2 \\
\hline Histidine & $1.67^{\mathrm{b}}$ & 0.12 & $1.92^{\mathrm{b}}$ & 0.11 & $1.26^{\mathrm{a}}$ & 0.11 & $1.91^{\mathrm{b}}$ & 0.10 & $<0.0001$ \\
\hline Hydroxyproline & 0.09 & 0.02 & 0.04 & 0.02 & 0.01 & 0.02 & 0.01 & 0.02 & 0.05 \\
\hline Isoleucine & 3.83 & 0.19 & 4.03 & 0.18 & 4.18 & 0.18 & 4.10 & 0.17 & 0.6 \\
\hline Leucine & 7.06 & 0.29 & 7.49 & 0.26 & 7.29 & 0.26 & 7.04 & 0.25 & 0.6 \\
\hline Lysine & 13.80 & 0.67 & 12.89 & 0.60 & 13.33 & 0.60 & 12.42 & 0.58 & 0.44 \\
\hline Methionine & $1.31^{\mathrm{a}}$ & 0.10 & $1.57^{\mathrm{ab}}$ & 0.09 & $1.70^{\mathrm{b}}$ & 0.09 & $1.36^{\mathrm{a}}$ & 0.08 & 0.01 \\
\hline Phenylalanine & 3.12 & 0.15 & 3.37 & 0.13 & 3.18 & 0.13 & 3.27 & 0.13 & 0.6 \\
\hline Proline & $3.87^{\mathrm{ab}}$ & 0.11 & $3.79^{\mathrm{a}}$ & 0.10 & $3.96^{\mathrm{ab}}$ & 0.10 & $4.21^{\mathrm{b}}$ & 0.09 & 0.02 \\
\hline Serine & $3.28^{\mathrm{a}}$ & 0.11 & $3.95^{\mathrm{b}}$ & 0.10 & $4.16^{\mathrm{b}}$ & 0.10 & $4.05^{\mathrm{b}}$ & 0.09 & $<.0001$ \\
\hline Threonine & 4.87 & 0.15 & 4.95 & 0.13 & 5.27 & 0.13 & 4.99 & 0.13 & 0.18 \\
\hline Tyrosine & 4.47 & 0.21 & 4.70 & 0.19 & 4.77 & 0.19 & 4.35 & 0.18 & 0.35 \\
\hline Valine & 6.59 & 0.27 & 6.37 & 0.25 & 6.51 & 0.25 & 6.68 & 0.24 & 0.84 \\
\hline
\end{tabular}


1 Supplementary Table 1. PCA was performed to study the correlation between amino acid

2 composition (\% of total amino acids) in the diet and milt of European eel, Anguilla anguilla,

3 where diets (DAN-EX, EH-4, EH-5, EH-6) were used as category variables. The cumulative

4 proportion of variance explained and factor loadings for two principle components are displayed.

\begin{tabular}{lccccc}
\hline & \multicolumn{2}{c}{ PC1 } & & \multicolumn{2}{c}{ PC2 } \\
\cline { 2 - 3 } \cline { 5 - 6 } Cumulative proportion & \multicolumn{2}{c}{0.430} & & \multicolumn{2}{c}{0.580} \\
DAN-EX & \multicolumn{2}{c}{-0.225} & & \multicolumn{2}{c}{0.013} \\
EH-4 & \multicolumn{2}{c}{0.045} & & \multicolumn{2}{c}{-0.074} \\
EH-5 & \multicolumn{2}{c}{0.090} & & \multicolumn{2}{c}{-0.251} \\
EH-6 & \multicolumn{2}{c}{0.080} & & \multicolumn{2}{c}{0.320} \\
& Milt & Diet & & Milt & Diet \\
Alanine & -0.035 & 0.219 & & 0.017 & -0.127 \\
Arginine & -0.048 & 0.157 & & -0.236 & 0.273 \\
Aspartic acid & -0.103 & -0.201 & & 0.063 & -0.126 \\
C-C & -0.059 & -0.225 & & -0.082 & 0.111 \\
Glutamic acid & -0.050 & -0.235 & & 0.105 & -0.019 \\
Glycine & 0.137 & 0.175 & & 0.088 & -0.175 \\
Histidine & 0.001 & 0.201 & & 0.283 & -0.182 \\
Hydroxyproline & -0.127 & 0.235 & & -0.023 & -0.020 \\
Isoleucine & 0.112 & -0.232 & & 0.124 & -0.051 \\
Leucine & 0.083 & -0.071 & & 0.027 & -0.352 \\
Lysine & -0.059 & 0.160 & & -0.116 & 0.268 \\
Methionine & 0.082 & -0.165 & & -0.176 & -0.064 \\
Phenylalanine & 0.052 & -0.210 & & 0.008 & -0.078 \\
Proline & 0.054 & 0.232 & & 0.205 & -0.046 \\
Serine & 0.201 & 0.225 & & 0.013 & -0.110 \\
Threonine & 0.137 & 0.202 & & 0.054 & -0.011 \\
Tyrosine & 0.032 & -0.222 & & -0.173 & 0.085 \\
Valine & 0.054 & 0.220 & & 0.249 & -0.053 \\
\hline
\end{tabular}

5

6

7

8 
14 Supplementary Table 2. PCA was performed to study the correlation between sperm

15 motility/velocity and amino acid composition (\% of total amino acids) in the milt of European

16 eel, Anguilla anguilla, where diets (DAN-EX, EH-4, EH-5, EH-6) were used as category

17 variables. The cumulative proportion of variance explained and factor loadings for two principle

18 components are displayed.

\begin{tabular}{lcc}
\hline & PC1 & PC2 \\
\hline Cumulative proportion & 0.27 & 0.43 \\
DAN-EX & -0.205 & 0.014 \\
EH-4 & 0.036 & 0.156 \\
EH-5 & 0.066 & 0.058 \\
EH-6 & 0.093 & -0.230 \\
Alanine & -0.012 & 0.058 \\
Arginine & -0.114 & 0.244 \\
Aspartic acid & -0.223 & -0.291 \\
C-C & -0.067 & 0.169 \\
Glutamic acid & -0.159 & -0.360 \\
Glycine & 0.323 & 0.054 \\
Histidine & 0.091 & -0.148 \\
Hydroxyproline & -0.243 & 0.015 \\
Isoleucine & 0.287 & 0.044 \\
Leucine & 0.291 & 0.186 \\
Lysine & -0.213 & 0.127 \\
Methionine & 0.196 & 0.224 \\
Phenylalanine & 0.267 & 0.176 \\
Proline & 0.059 & -0.260 \\
Serine & 0.232 & 0.030 \\
Threonine & 0.232 & -0.034 \\
Tyrosine & 0.148 & 0.334 \\
Valine & 0.118 & -0.225 \\
Motility 10 s (MOT10) & 0.266 & -0.194 \\
Curvilinear velocity 10 s (VCL10) & 0.125 & -0.230 \\
Motility 20 s (MOT20) & 0.226 & -0.208 \\
Curvilinear velocity 20 s (VCL10) & 0.160 & -0.224 \\
Motility 30 s (MOT30) & 0.218 & -0.193 \\
\hline & & \\
& & \\
& & \\
& & \\
& &
\end{tabular}

